\title{
ESTABILIDADE FENOTÍPICA DE VARIEDADES DE CANA-DE-AÇÚCAR (Saccharum spp.) NOS ESTADOS DE PERNAMBUCO E RIO GRANDE DO NORTE
}

\section{CARLOS EDUARDO LINS E SILVA PIRES}

Orientador: Prof. Dr. Natal Antonio Vello

Dissertação apresentada à Escola Superior de Agricultura "Luiz de Queiroz", da Universidade de São Paulo, para obtenção do titulo de Mestre em Genética e Melhoramento de Plantas.

$P I R A C I C A B A$

Estado de São Paulo - Brasil

Fevereiro - 1981 
ii.

"In memorian" de minha irmã Vesta

OFEREÇO.

A minha esposa Mizu

A meu fizho Aldo

Aos meus pais

DEDICO. 
Ao professor Natal Antonio Vello, pela orientação, ensinamentos, estímulo e ámizade.

Ao Engo Agrọ Mário Marreira de Melo, pelos primeiros ensinamentos sobre Melhoramento da Cana-de-Açūcar.

A Superintendēncia do Programa Nacional do Melhoramento da Ca na-de-Açūcar (PLANALSUCAR) e à Escola Superior de Agri cultura "Luiz de Queiroz" pela oportunidade do treinamento.

Aos professores do Departamento de Genética da Escola Supe rior de Agricultura "Luiz de Queiroz", pelos ensinamentos e amizade.

Ao Engo Agro Norberto Lavorenti, pela colaboração nas análises estatisticas.

Aos Engenheiros Agrōnomos Francisco de Melo Albuquerque, Dr. Renato Ruschel, Dr. José Alberto Gentil de Souza e Dr. Hasime Tokeshi, pelas facilidades.

Aos Engenheiros Agrōnomos Josē Alberto Marroquim e Gerson Qui rino Bastos, pela colaboração na condução dos trabaIhos de campo.

Aos Engenheiros Agrōnomos Antonio Maria Cardoso Rocha, Marce10 de Menezes Cruz e Dr. Clóvis Lemos Veiga, pelo convivio e amizade. 
Aos colegas de curso pelos estímulos e amizade.

Aos demais, que contribuíram direta ou indiretamente, para a realização deste trabalho. 
4. RESULTADOS $\ldots \ldots \ldots \ldots \ldots \ldots \ldots \ldots \ldots \ldots \ldots \ldots \ldots \ldots \ldots \ldots \ldots \ldots \ldots$

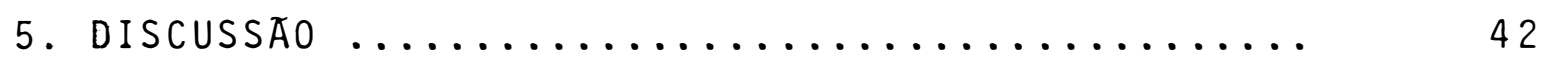

5.1. Considerações gerais ............... 42

5.2. Caracterização de ambientes ........... 44

5.3. Avaliação da estabilidade fenotípica ...... 45

5.4. Avaliação da repetibilidade dos parámetros de estabilidade $\ldots \ldots \ldots \ldots \ldots \ldots \ldots$

6. CONCLUSOES $\ldots \ldots \ldots \ldots \ldots \ldots \ldots \ldots \ldots \ldots \ldots \ldots \ldots \ldots \ldots$

7. Literatura CitAdA ..................... 60

8. APENDICE $\ldots \ldots \ldots \ldots \ldots \ldots \ldots \ldots \ldots \ldots \ldots \ldots \ldots \ldots \ldots \ldots \ldots \ldots \ldots \ldots$ 


\section{LISTA DE STABELAS}

Pàg.

TABELA 1 - Variedades de cana-de-açūcar estudadas, seus progenitores e suas procedencias ....

TABELA 2 - Distribuição dos experimentos estudados e suas respectivas datas de plantio e co Theita do primeiro e segundo cortes ......

TABELA 3 - Anālise conjunta de variāncia, para $\underline{S} e \underline{x}$ perimentos, cada um com I variedades e R repetições, para cada corte ...........

TABELA 4 - Anālise conjunta de variāncia, em parce las subdivididas no tempo, para $\underline{S}$ experimentos, cada um com I variedades, $\underline{R}$ re

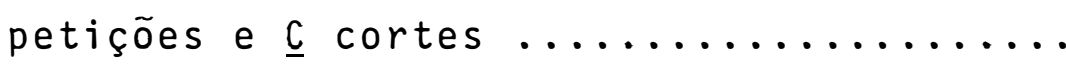

TABELA 5 - Anālise de variāncia para estabilidade, considerando $\underline{S}$ ambientes e $I$ variedades (modelo adaptado de EBERHART e RUSSEL, $1966) \ldots \ldots \ldots \ldots \ldots \ldots \ldots \ldots \ldots \ldots \ldots \ldots \ldots \ldots \ldots \ldots \ldots \ldots \ldots \ldots$

TABELA 6 - Anālise de variāncia em blocos ao acaso, considerando G grupos e I variedades, pa

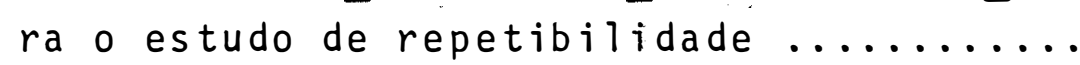

TABELA 7 - Anālises conjuntas de variāncia em blocos casualizados de 29 experimentos, com seis variedades de cana-de-açūcar e qua tro repetições, considerando o primeiro e segundo cortes separadamente ........ 
Pàg.

TABELA 8 - Anālise conjunta de variàncila em parce 1 as subdivididas no tempo, de 29 experimentos, com seis variedades, quatro

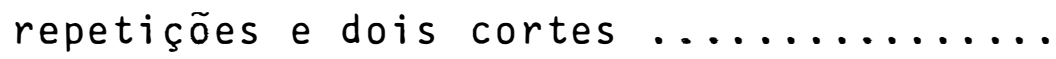

TABELA 9 - Anālise conjunta da produção média de colmos de seis variedades ce cana-de-a çúcar, considerando os 29 àmbientes do primeiro corte (modelo adaptado de EBERHART e RUSSEL, 1966) ................

TABELA 10 - Anālise de variāncia da produção média de colmos de seis variedades de canade-açūcar, considerando os 29 ambien tes do segundo corte (modeio adaptado de EBERHART e RUSSEL, 1966; ............

TABELA 11 - Anālise de variāncia da produção média de colmos de seis variedades de canade-açūcar, considerando o total de 58 ambientes de dois cortes (modelo adaptado de EBERHART e RUSSEL, 1966) .......

TABELA 12 - Produções médias (TCH), coeficientes de regressão (b) variāncia dos desvios $\left(s^{2}\right)$ e coeficientes de determinação $\left(R^{2}\right)$ de seis variedades, considerando 58 ambientes (29 experimentos de cada

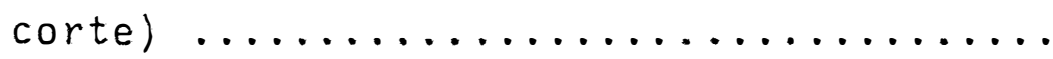


TABELA 13 - Produções médias (TCH), coeficientes de regressão (b), variāncia dos desvios da regressão $\left(s^{2}{ }_{d}\right)$ e coeficientes de determinação $\left(R^{2}\right)$, para 29 ambientes de

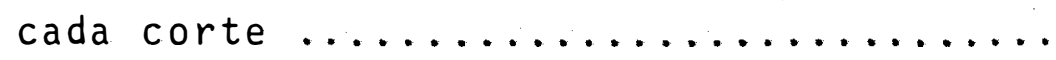

TABELA 14 - Anālise de variāncia em blocos casuali zados, estimativas da variāncia genéti ca $\left(\bar{\sigma}_{g}^{2}\right)$, coeficiente de variāncia $(C V \%)$, coeficiente de repetibilidade $\left(r_{j}\right)$ e seu erro $\left[s\left(r_{j}\right)\right]$, para produção média, no primeiro corte, segundo corte e nos dois cortes conjuntamente ...............

TABELA 15 - Anāilise de variāncia em blocos casuali zados, estimativas da variāncia genéti ca $\left(\bar{\sigma}^{2}\right)$, coeficiente de variação (CV\%), coeficiente de repetibilidade $\left(r_{i}\right)$, e seu erro [s $\left.\left(r_{i}\right)\right]$ para os valores de $\underline{b}$, no primeiro corte, segundo corte e nos

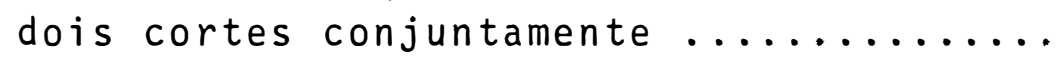

TABELA 16 - Anālise de variāncia em blocos casuali zados, estimativas da variāncia genéti ca $\left(\bar{\sigma}_{g}^{2}\right)$, variāncia ambiental $\left(\bar{\sigma}^{2}\right)$, coe ficientes de variação ( CV\%), coeficien te de repetibilidade $\left(r_{j}\right)$ e seu erro [s $\left(r_{j}\right)$ ] para os valores das variāncias dos desvios da regressão $\left(s_{d}{ }_{d}\right)$, no pri meiro corte, segundo corte e nos dois

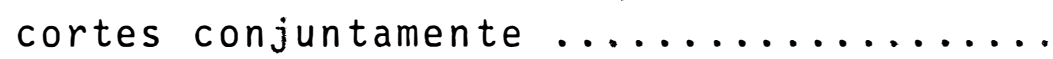




\section{LISTA DE FIGURAS}

Pāg.

FIGURA 1 - Regressão linear da produção de cana-deaçūcar das seis variedades em 58 ambien-

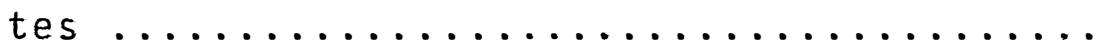

FIGURA 2 - Relação entre a produção média de cana de-açūcar e coeficientes de regressão $1 \underline{i}$ near de seis variedades em 58 ambientes ... 


\title{
ESTABILIDADE FENOTİPICA DE VARIEDADES DE CANA-DE-ACUŪCAR (Saccharum spp.) NOS ESTADOS DE PERNAMBUCO E RIO GRANDE DO NORTE
}

\author{
CARLOS EDUARDO LINS E SILVA PIRES
}

NATAL ANTONIO VELLO

orientador

\section{RESUMO}

A partir dos dados obtidos em dois cortes de 29 experimentos distribuídos por sete locais dos Estados de Pernambuco e Rio Grande do Norte e compreendendo os anos agrícolas $73 / 74$ a $75 / 76$ para o primeiro corte e $74 / 75$ a $76 / 77$ para o segundo corte, foi realizado o estudo de estabilidade fenotĩpica para produção de colmos de seis variedades de cana-deaçūcar, de acordo com o modelo proposto por EBERHART e RUSSEL $(1966)$.

A significāncia da interação "variedades $x$ experimentos" nas anālises conjuntas de variāncia em blocos ao acaso, considerando cada corte separadamente, indicou que os 29 experimentos (locais e anos) devem ser considerados como ambientes distintos nas anālises de estabilidade. A signifi cância das interações "variedades $x$ cortes" e "variedades $x$ cortes x experimentos", detectada na anālise conjunta de va- 
riāncia dos 29 experimentos com os dois cortes em parcelas sub divididas no tempo, indicou que cada corte deve ser considera do como um ambiente distinto no estudo da estabilidade fenotí pica.

A anāilise de variāncia para estabilidade, considerando o total de 58 ambientes (os dois cortes dos 29 expe rimentos), mostrou que a produção média das seis variedades responderam às variações ambientais de forma predominantemente linear e que as variedades apresentaram diferenças genéticas para produção, adaptação e estabilidade.

As variedades CB45-3 e CB61-27 apresentaram mais alta capacidade de produção, tendéncias de adaptação a ambientes favorāveis $(b>1)$ e variāncia dos desvios da regressão significativos mas com magnitudes inferiores à média das variāncias de todas as variedades estudadas. Foi realçado o fato da variedade CB61-27 apresentar dois aspectos desfavorāveis: menor teor de sacarose e suscetibilidade à escaldadura da folha, Xanthomonas albilineans (Ashby) Dowson. Jà as variedades CB47-355 e CB55-18 apresentaram valores de b semelhante à unidade e as menores variáncias dos desvios da regressão. To davia, ambas as variedades apresentaram produções inferiores à produção média das variedades estudadas. Finalmente, as varie dades CP51-22 e CP53-76 mostraram tendēncias de adaptação às condições menos favorāveis $(b<1)$ e comportamento dos mais imprevisiveis, por terem apresentado as maiores variāncias dos desvios da regressão. 
As anālises de estabilidade, para cada corte separadamente, mostraram tendéncias mais estāveis das varieda des no segundo corte. Dessa maneira, não é recomendāvel avaliar a estabilidade fenotípica de variedades de cana-de-açū car com base num ūnico corte.

o estudo de repetibilidade indicou que a seleçāo em cana-de-açūcar deve ser promissora no sentido de se al terar tanto a produção, como tambēm as respostas lineares e não-lineares às variações ambientais. 
xi i i .

\title{
PHENOTYPIC STABILITY OF SUGARCANE (Saccharum spp.) VARIETIES AT PERNAMBUCO AND RIO GRANDE DO NORTE STATES
}

\author{
CARLOS EDUARDO LINS E SILVA PIRES
}

NATAL ANTONIO VELLO

Adviser

SUMMARY

Six sugarcane varieties were evaluated for yield stability in 29 experiments. These experiments were carried out in randomized blocks with four replications in seven different locations of Pernambuco and Rio Grande do Norte States. Data relating to tons cane/ha were obtained during 1973/74 to 1975/ 76 from cane plant harvests and $1974 / 75$ to $1976 / 77$ from first ratoon harvests. EBERHART and RUSSEL'S (1966) model was used to evaluate phenotypic stability of the varieties.

Based on the significance of the interactions of joint analysis of variance the 29 experiments (locations and years) and the two types of harvest (cane plant and first ratoon) were taken as distinct environments for the stability study.

Relative performance of varieties varied according to along the environments but cane yields were largely explained 
xiv.

by linear regression. In spite of this fact, significant deviations from regression were detected for all varieties.

Varieties $C B 45-3$ and CB61-27 showed the highest

performance level for cane yield over environments, goodyielding capacity for favorable environments $(b>1)$ and small deviations from the regression. However, CB61-27" is not recommended due to its low sucrose content and susceptibility to leaf scald (Xanthomonas albilineans) (Ashby) Dowson.

Varieties CB47-355 and CB55-18 have $b=1$ and

the lowest deviations from the regression. However, these varieties present mean yield below the general average.

The other two varieties CP51-22 and CP53-76 showed adaptation to poorer environments $(b<1)$ and the highest deviations from the regression.

From the results obtained for each type of harvest it was possible to observe that the varieties showed morestable response at first ratoon level than cane plant level. So it is not recommended to evaluate the phenotypic stability of sugarcane varieties based on one harvest only.

The repeatibility study indicated that sugarcane selection is promising for altering yield linear response and deviations from regression. 


\section{INTRODUÇÃO}

A cana-de-açūcar (Saccharum spp.), sempre foi considerada como uma das culturas de maior importāncia económica no Brasil, em função da produção de açūcar, que há muitos anos tem gerado divisas ao país. A sua importāncia tem au mentado, à medida em que se agrava o problema energētico mundial e o económico nacional com a realidade da utilização do álcool para substituir o petrōleo em boa parte, evitando - se a importação deste, e assim equacionando a crescente dívida externa.

O governo brasileiro vem desenvolvendo intenso programa para a produção de ālcool a partir da cana-de-açūcar, pretendendo atingir a meta de 10,7 bilhões de 1 itros de álcool em 1985. Um programa deste porte coloca o Brasil na van guarda internacional. Para se alcançar esta meta torna-se necessāria a expansão do cultivo da cana-de-açūcar tanto em áreas tradicionais como em áreas novas e, ainda, o desenvolvimento de pesquisas para aumentar os indices de produtividade 
nas āreas tradicionais e garantir indices satisfatōrios nas áreas novas.

Com o objetivo de aumentar os indices de produ tividade, vem o IAA-PLANALSUCAR desenvolvendo desde 1971, um programa de melhoramento para todo o Brasil, tendo como objetivo principal a criação de novas variedades. A introdução de variedades de outros centros canavieiros também è feita, sendo as mesmas submetidas a ensaios juntamente com as variedades locais, podendo ser ou não recomendadas para o plantio co mercial, além de enriquecerem o Banco de Germoplasma desta insti tuição.

Um programa de melhoramento deve conter, alēm da procura de variedades adaptadas às condições específicas de determinados ambientes, a busca de variedades com capacidade de explorar economicamente amplas faixas ambientais. Sendo assim, técnicas para avaliar a capacidade genética de adaptação ampla ou específica e o desempenho das variedades frente às variações ambientais devem fazer parte de um programa de melhoramento.

0 estudo de estabilidade fenotípica, permite sintetizar em poucos parámetros o enorme volume de informa ções obtidas de um grande nümero de experimentos, distribuídos em locais e anos agrícols diferentes. Estes parámetros caracterizam a capacidade produtiva, o tipo de adaptação e a estabilidade das variedades envolvidas nos experimentos, faci 1 itando a recomendação de variedades. 
O objetivo deste trabajtho foi avaliar a estabi lidade fenotípica de seis variedades de cana-de-açūcar e, tam bém, detalhar a metodologia para utilização desta técnica em programas de melhoramento de cana-de-açūcar. 


\section{REVISÃO DE LITERATURA}

A presente revisão se refere a alguns aspectos gerais do fenōmeno da interação de genōtipos por ambientes, dando maior ēnfase aos métodos utilizados para avaliar genóti pos frente às variações ambientais.

ALLARD e BRADSHAW (1964) classificam a variação ambiental em duas categorias: Previsĩvel e imprevisível. A primeira categoria se refere às características permanentes do ambiente, tais como, caracteres gerais do clima e algumas caracteristicas que flutuam sistematicamente como comprimento do dia e outros. Também se incluem nesta categoria os aspectos am bientais que são diretamente influenciados pelo homem, tais como data e densidade de semeadura, doses e formas de adubação, métodos e épocas de colheitas e outras práticas agronōmicas. As variações imprevisĩveis correspondem as flutuações do clima como quantidade e distribuição de chuvas, temperatura e ou tros fatores. 
A existéncia da interação de genōtipos por ambientes tem se constituĩdo em um importante problema nos programas de melhoramento de plantas. COMSTOCK e MOLL (1963) estabeleceram que interações altas de genōtipos por ambientes, tēm reduzido os progressos na seleção. TAI (1971) trabalhando com batata, apresenta duas alternativas para minimizar o efeito destas interações. A primeira alternativa consiste na subdivisão de uma ārea heterogénea em sub-regiões as mais homogê neas possíveis. A segunda alternativa se refere à utilização de genótipos com alta estabilidade fenotípica. 0 autor ainda comenta que a primeira alternativa não deve ser muito eficien te em virtude de continuar aparecendo interações altamente significativas, como de genōtipos por anos, que não podem ser re duzidas com a subdivisão da àrea.

Na cultura da cana-de-açūcar jā foi constatada a existéncia de interação de genōtipos por ambientes. De acor com com SKINER (1971), as interações de genōtipos por anos e por locais tém aparentemente, importante influéncia no compor tamento de variedades. FANGUY (1971) mostra que existe intera ção significativa de variedades por datas de colneita, quando se considera o carāter fragilidade do colmo, importante para colheita mecanizada.

A existéncia de interação de genōtipos por ambientes tambēm foi relatada por PIRES e COSTA (1980), através de estudo de correlações entre componentes da produção em qua tro locais da região canavieira de Pernambuco. 
Considerando que diferentes ambientes lēpocas de plantio, idades de corte, anos e locais) afetam significativamente as médias, variāncias e o grau de determinação genē tica, MARIOTTI (1974 e 1980) sugere que os trabalhos de seleção sejam desenvolvidos em diferentes condições de ambientes, no sentido de se conseguir genótipos adaptados a cada ambiente específico. Deve-se considerar que os trabalhos de MARIOTTI (1974 a 1980) foram conduzidos na Argentina, onde as varia ções ambientais não são tão acentuadas como as existentes no Brasil.

A extensa ārea cultivada com cana-de-açūcar no Brasil, foi estratificada em quatro regiões (Norte, Sul, Leste e Nordeste), distintas por macrodiferenças ecolōgicas, pe10 Programa Nacional do Melhoramento da Cana-de-Açūcar (PLANALSUCAR). Dessa forma, os programas de melhoramento são distintos para cada região. Apesar da estratificação, ainda permanece uma variação ambiental significativa dentro de regiões. Dessa forma, torna-se inviāvel a obtenção de genōtipos especī ficos para os diferentes ambientes. Considerando a fase atual do melhoramento de cana-de-açūcar no Brasil, seria mais recomendāvel a obtenção de variedades estāveis, com adaptação satisfatória aos diferentes ambientes de uma região em particular. Em vista disso, torna-se importante a determinação da es tabilidade fenotipica das diferentes variedades.

Conforme o relatado por OLIVEIRA (1976.) o méto do mais antigo para determinar estabilidade fenotípica, con- 
siste na anālise de grupos de experimentos. Através desta anā lise, a magnitude das interações é avaliada pelas variāncias dos efeitos: genótipos por anos, genótipos por locais e genótipos por anos e locais. Segundo FINALY e WILKINSON (1963), este método é adequado para indicar as existencias das intera ções, mas de baixa precisão, como medida bāsica de adaptabili dade, além de ser de difícil uso quando se avalia umgrande nú mero de genótipos.

0 método para decompor a interação de genōtipos por ambientes, atravēs da anālise de regressão foi estabe lecido por YATES e COCHRAN (1938) para estudo de cultivares conduzidos em anos e locais diferentes. Esta metodologia ficou esquecida cerca de 20 anos, até que FINLAY e WILKINSON (1963) adaptaram esta técnica para avaliar a estabilidade da produção de cultivares de cevada, considerando cada local ou ano como um ambiente. De início, estes autores estabeleceram indices ambientais $\left(I_{j}=\bar{X}_{j}-\overline{\bar{X}}\right)$, onde:

$$
\begin{aligned}
\bar{X}_{j}= & \text { média aritmética de todas as I cultivares no am- } \\
& \text { biente } j, \text { com } j=1,2 \ldots J ; \\
\overline{\bar{X}}= & \text { média geral do carāter, considerando todas as I } \\
& \text { cultivares e os J ambientes. }
\end{aligned}
$$

A seguir, determinaram coeficiente de regressão linear ( $b_{i}$, com $i=1,2 \ldots$ I, cultivares) entre a média da cultivar i em cada ambiente e os indices ambientais corres pondentes. De acordo com FINLAY e WILKINSON (1963) uma culti- 
var é considerada estável quando possuir $b=0$ (zero). Por es tes autores, as cultivares são caracterizadas por dois parāme tros: comportamento médio em todos os ambientes e coeficiente de regressão b. A cultivar ideal seria aquela que apresentas-se produção média superior e $b=0$.

0 método da regressao foi também utilizado por EBERHART e RUSSEL (1966), em milho, que introduziram um terceiro paràmetro para caracterizar as cultivares: a variáncia dos desvios da linearidade $\left(s_{d}^{2}\right)$. Para estes autores, uma variedade ideal seria aquela que apresentassse: produção média superior, $b=1$ e $s_{d}^{2}=0$.

Em relação ao método de FINLAY e WILKINSON (1963), o método de EBERHART e RUSSEL (1966) teria algumas van tagens: a primeira vantagem se refere ao coeficiente de regres são linear: cultivar com $b=1$ teria potencial para responder à melhoria do ambiente, por exemplo através de insumo agrícola, fato que não é esperado para cultivares com b $=0$ Esta vantagem assume importāncia maior quando se considera o fato de que normalmente $b=0$ está associado com produções inferiores, ou seja adaptação a ambientes relativamente pobres. A segunda vantagem está relacionada à variāncia dos desvios da linearidade: uma cultivar com $s_{d}^{2}=0$ apresentaria padrão estável de resposta à melhoria ambiental.

outros métodos baseados na regressāo linear pa ra avaliar os efeitos genéticos, ambientais e as suas interações usando linhagens puras e as gerações obtidas pelos seus 
cruzamentos foram propostos.

BUCIO ALANIS (1966) utilizou um método que per mite estimar os efeitos genéticos, ambientais e a interação en tre eles, a partir de um par de linhas puras de Nicotiana rus tica. O autor considera o método de grande utilidade, pois per mite estimar com maior precisão a herdabilidade e o ganho na seleção. BUCIO ALANIS e HILL (1966), na mesma cultura, utilizaram este método considerando alēm das linhas puras, a geração $F_{1}$. Outra adaptação foi feita por BUCIO ALANIS etalii (1969) ainda com Nicotiana rustica, com a finalidade de incorporar ao método o estudo da geração $F_{2}$ e dos retrocruzamentos. PERKINS e JINKS (1968) utilizaram este método adaptado para o estudo de värias linhas puras de Nicotiana rustica e seus cruzamen tos.

BHULLAR et alii (1977) aplicando a técnica de regressão nas anāilises das gerações $F_{1}$ a $F_{5}$ obtidos pelos cru彑 zamentos possíveis entre sete variedades de trigo, mostraram que a estabilidade fenotípica está associada com a constituição genética dos pais e com os nîveis de heterozigosidade e he terogeneidade das populações. Apontaram ainda a possibilidade de combinar produções superiores com elevado grau de estabil dade.

TAI (1971) estudando variedades de batata, des creve um método semelhante ao de EBERHART e RUSSEL (1966) diferindo deste na maneira de estimar os parāmetros de estabili dade. Para estimar o parāmetro linear $\alpha_{j}$ utiliza-se a cova- 
riāncia entre os efeitos de ambientes e os da interação genótipos por ambientes, dividido pela variāncia dos efeitos ambientais. 0 parāmetro do efeito não linear $\lambda_{j}$ é estimado pela razão entre a variāncia dos desvios da resposta linear e a va riāncia do erro associado aos efeitos da interação genótipos por ambientes. Neste método uma variedade é considerada estável quando $\alpha=-1$ e $\lambda=1$, e uma variedade $\bar{e}$ consideradade e tabilidade média quando $\alpha=0$ e $\lambda=1$.

BILBRO e RAY (1976) estudando cultivares de al godão, propuseram o uso do coeficiente de regressão para medir a adaptabilidade e o coeficiente de determinação para me dir a estabilidade. Os autores revelam que estes dois parámetros associados a alta produção média são eficientes para ava liar o comportamento das variedades frente às variações ambientais.

Existem outros métodos propostos para o estudo da estabilidade fenotípica, não tendo como base a anālise de regressão linear.

PLAISTED e PETERSON (1959), estudando varieda des de batata,propuseram estimar um parāmetro de estabilidade para cada genótipo a partir das análises de grupos de experimentos. Consideraram inicialmente os resultados de um ano, rea lizando a anālise da variāncia conjunta envolvendo todos os ge nótipos e locais. Se a interação genótipos por locaisfor significativa realizam-se as anālises de variāncia conjunta para cada combinação dos genótipos dois a dois. O genótipo conside 
rado mais estável seria aquele que apresentasse a menor variān cia mēdia da interação de genōtipos por ambientes.

PLAISTED (1960) propōs fazer anāiises conjunitas de variáncia omitindo de cada vez um genōtipo. Assim para cada anālise em que se omite um genōtipo diferente, estima-se a interação de genōtipos por ambientes. A magnitude da intera ção em cada anālise indica a estabilidade do genótipo omiti do. 0 genōtipo omitido será considerado tanto mais estável quan to maior for a magnitude desta interação.

De acordo com OLIVEIRA (1976) um outro método para avaliação de genōtipos, denominado "ecovaléncia" foi introduzido em 1965 por G. Wricke. Este método estima o parāmetro $\bar{W}_{j}$ que avalia as oscilações de cada genōtipo frente às va riações ambientais. A variedade considerada mais estável ē a que apresenta o menor valor de $\bar{W}_{j}$.

A comparação dos diversos métodos para avaliar a estabilidade fenotípica tem sido feita por diversos autores.

KALTSIKES e LARTER (1970) utilizaram os métodos de FINLAY e WILKINSON (1963), EBERHART e RUSSEL (1966), BU CIO ALANIS (1966), BUCIO ALANIS e HILL (1966) e PERKINS e JINKS (1968) na cultura do trigo, concluindo que todos os métodos tém utilização vāi ida.

outro estudo de comparação dos métodos de FINLAY e WILKINSON (1963), EBERHART e RUSSEL (1966) e G. Wricke (1965) foi desenvolvido na cultura do sorgo por JOWETT (1972). 
o autor conclui que o método de EBERHART e RUSSEL (1966) deve ser preferido por ser mais explicito, mas que o de FInLAY e WILKINSON (1963) deve ser utilizado quando os genótiposiusados tiverem produções bastante diferentes, em virtude de se trabalhar em escala logaritmica, fato que aumenta a homogenei dade dos desvios.

OLIVEIRA (1976) utilizando dados de produção de milho comparou os métodos: tradicional; PLAISTED e PETERSON (1959), FINLAY e WILKINSON (1963); G. Wricke (1965); EBERHART e RUSSEL (1966) e TAI (1971), considerou que de uma maneira ge ral houve concordäncia entre os resultados obtidos. No entanto, ressalta que os métodos de EBERHART e RUSSEL (1966) e FIN LAY e WILKINSON (1963) parecem fornecer maiores informações.

Na aplicação da técnica de regressão, tem sido considerado várias modalidades de ambientes. A utilização de apenas um mesmo local ou de apenas locais dentro de um mesmo ano, como ambientes diferentes tem sido feita. No entanto, é mais comum a utilização de locais e anos como ambientes diferentes (FINLAY e WILKINSON, 1963; EBERHART e RUSSEL, 1966; BO NATO, 1978; SANTOS, 1980). Também jā foram considerados outros tipos de ambientes: BREESE (1969) utilizou diferentes cortes, realizados em locais e anos diferentes em Dactylis glomerata, uma graminea forrageira; EASTON e CLEMENT (1973) empregaram diferentes doses de fertilizantes como ambientes para estudar estabilidade em cultivares de trigo; MONTEIRO (1975) considerou diferentes épocas de plantio e colheiras como am- 
bientes para estudar estabilidade em berinjela.

Na cultura da cana-de-açūcar, apesar de SKINER (1971) comentar que a técnica da regressão se apresentava como um promissor método para avaliar variedades frente às variações ambientais, poucos trabalhos foram apresentados sobre o assunto até o momento: POLLOCK (1975) considerando locais, anos e cortes como ambientes contrastantes e avaliando a esta bilidade fenotípica pelos parāmetros de EBERHART e RUSSEL (1966), de trés variedades utilizadas como padrões na Austrália, conclui que é preferível fazer seleção de clones em expe rimentos com repetições utilizando a média das trés variedades como padrão, do que qualquer uma delas sozinha, por apresentar maior estabilidade.

MARIOTTI et alii (1976) estudando a estabilida de de variedades de cana-de-açūcar na Argentina, utilizaram os dados de cinco cortes de 17 experimentos instalados em um mesmo local, englobando um período de 15 anos. Os parāmetros utilizados neste estudo foram coeficiente de regressão linear $\left(b_{x y}\right)$; coeficiente de variação da linha da regressão (CV $x y$ ) ; e o coeficiente de determinação $\left(R^{2}\right)$. Os autores afirmam que: a resposta aos estímulos ambientais para a maioria dos genōtị pos apresenta alta linearidade. Quando a análise de estabilidade foi feita para cada corte separadamente, o segundo corte apresentou uma maior estabilidade. Como não houve uma concordāncia geral de um corte para outro, os autores estabeleceram que a estabilidade nas condições da Argentina deve ser avalia 
da em função das médias dos diversos cortes.

Os métodos de G. Wricke (1965), EBERHART e RUS SEL (1966), BILBRO e RAY (1976) foram comparados por GALVEZ (1980) em cana-de-açūcar. 0 emprego do coeficiente de correla ção de Kendal mostrou associação positiva entre: ecovaléncia e variancia dos desvios da linearidade; ecovalència e coefi ciente de determinação; coeficiente de determinação e variāncia dos desvios da linearidade.

No Brasil, apenas dois trabalhos para avaliar estabilidade fenotīpica em cana-de-açūcar, foram publicados. o primeiro apresentado por RUSCHEL (1977), que utilizou dados de produção obtidos no primeiro corte de trés grupos de experimentos, instalados na Estação Experimental de Campos (RJ), do Ministério da Agricultura, nos anos 1956/57, 1964 e 1970. 0 autor considerou os parāmetros de EBERHART e RUSSEL (1966) estabelecendo que, apesar da variedade CB45-3 apresentar um ni vel ótimo de estabilidade, é melhor utilizar a média das variedades CB45-3 e CB56-20 como padrão, para selecionar clones, por apresentar melhor estabilidade. CALHEIROS (1978) estudando a estabilidade de variedades em Alagoas, utilizou um método semelhante ao da anālise de grupos de experimentos, con cluindo que para o programa de melhoramento regional é melhor utilizar a média das variedades CB45-3 e Co331, por apresentar maior estabilidade do que quando se considera qualquer destas variedades sozinhas.

Como se observa, tanto em cana-de-açūcar como 
em outrais culturas, os diversos métodos tēm se mostrado üteis em avaliar a estabilidade de variedades frente às variações ambientalis. A maioria dos autores tem apontado o método de EBERHART e RUSSEL (1966) como o mais promissor. De maneira ge ral, a técnica da regressão pode contribuir positivamente, no sentido de melhorar a eficiéncia dos programas de melhoramento. 


\section{MATERIAL E MÉTODOS}

Para a realização deste estudo foram utilizados os dados de produção de colmos de seis variedades de cana-de-açūcar considerando o primeiro e segundo cortes de 29 ex perimentos, conduzidos nas regiões canavieiras dos Estados de Pernambuco e Rio Grande. do Norte.

\subsection{VARIEDADES E EXECUçÃo EXPERIMENTAL}

Os experimentos conduzidos na Coordenadoria Re gional Norte do IAA/PLANALSUCAR originalmente eram constituÍ dos por oito tratamentos. Para o presente estudo consideraramse as seis variedades que estavam presentes em todos os experimentos. A relação das variedades estudadas com seus respectivos progenitores e procedéncias é apresentado na Tabela 1. 
TABELA 1 - Variedades de cana-de-açūcar estudadas, seus progenitores e suas procedēncias.

Variedades

\section{Progenitores}

Feminino Masculino

Procedências

\begin{tabular}{|c|c|c|}
\hline CB45-3 & Co290 x Co 331 & Estação Exp. de Campos - BR \\
\hline CB47-355 & P0J2878 $\times$ Co213 & Estação Exp. de Campos - BR \\
\hline CB55-18 & CB40-69 $\times ?$ & Estação Exp. de Campos - BR \\
\hline CB61-27 & P0J2878 x Co331 & Estação Exp. de Campos - BR \\
\hline CP51-22 & F36-819 x CP33-372 & Canal Point, Flörida - USA \\
\hline CP53-76 & $\mathrm{F} 36-819 \times \mathrm{CP} 36-46$ & Canal Point, Flōrida - USA \\
\hline
\end{tabular}

distribuidos pelos Estados de Pernambuco e Rio Grande do Norte, foram conduzidos nos seguintes anos agrícolas: 1973/74, 1974/75, 1975/76, para o primeiro corte e 1974/75, 1975/76, 1976/77 para o segundo corte. A distribuição dos experimentos por local e datas de plantio e colneita está apresentada na Tabela 2. As caracterīsticas climāticas e geogrāficas dos sete locais estão apresentados no Apēndice 4.

os experimentos foram instalados em blocos ao acaso com quatro repetições dos tratamentos. 0 tamanho da par cela foi de seis sulcos de 11 metros, espaçados de 1,40 metros.

Os tratos culturais, tais como adubações, capinas, etc., foram feitos de acordo com o usual de cada 1 ocal. os dados foram obtidos da colheita dos quatro sulcos centrais 
de cada parcela em $\mathrm{kg} / 6 \mathrm{~J}, 6 \mathrm{~m}^{2}$ e transformados em TCH (toneladas de cana por hectare).

TABELA 2 - Distribuição dos experimentos estudados e suas respectivas datas de plantio e colheita do primeiro e segundo cortes.

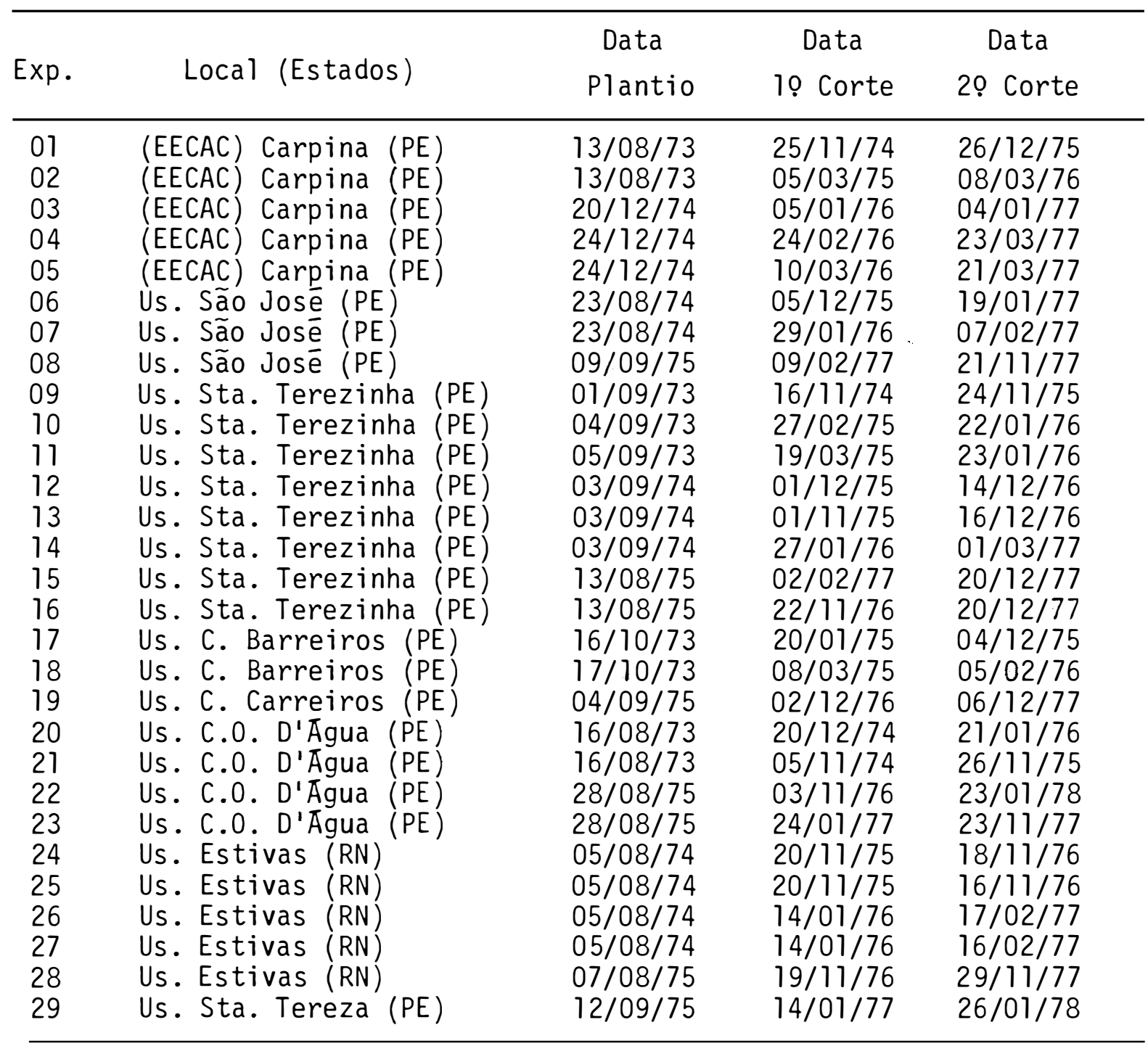

EECAC = Estação Experimental de Cana-de-Açūcar de Carpina; Us. - Usina. 


\subsection{Procedimentos Estatísticos}

Inicialmente foram feitas as anālises individuais de variáncia de acordo com o delineamento em blocos casualizados. Em seguida obtiveram-se as anālises conjuntas dos 29 experimentos, para cada corte separadamente, Tabela 3. Nes ta tabela, as esperanças matemáticas dos quadrados médios foram obtidas pelo método de BENNETT e FRANKLIN (1963), conside rando: como aleatório os efeitos de experimentos e blocos; e como fixo o efeito de variedades.

Estas anālises permitem o teste da significāncia do quadrado médio da interação (variedades xexperimentos) e dessa forma, pode-se verificar se os experimentos devem ou não ser considerados como ambientes diferentes em cada corte.

Em alguns experimentos, foi necessārio estimar parcela perdida, tendo sido utilizados os procedimentos relatados por PIMENTEL GOMES (1976). Para cada parcela perdida, di minuiu-se um grau de liberdade do residuo.

Para avaliar o efeito de cortes e de suas inte rações foi considerado inicialmente o delineamento de parcelas subdivididas no tempo para cada experimento (STELL e TORRIE, 1960). Em seguida, realizou-se a anālise conjunta para os 29 experimentos, cujo esquema se encontra na Tabela 4 . Nes ta tabela, as esperanças matemáticas dos quadrados médios foram obtidas pelo método de BENNETT e FRANKLIN (1963), conside rando: como aleatórios os efeitos de experimentos e blocos; 


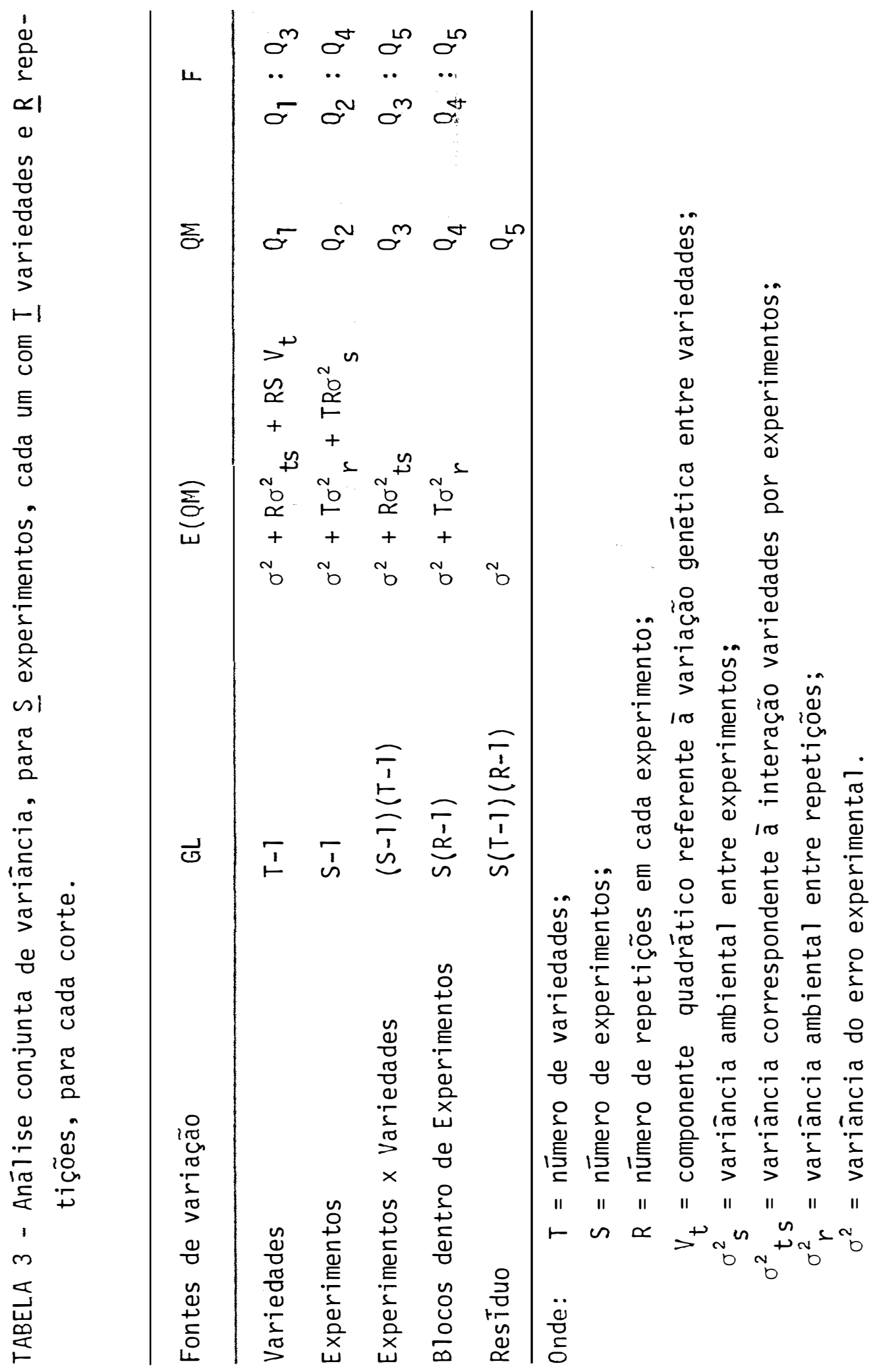




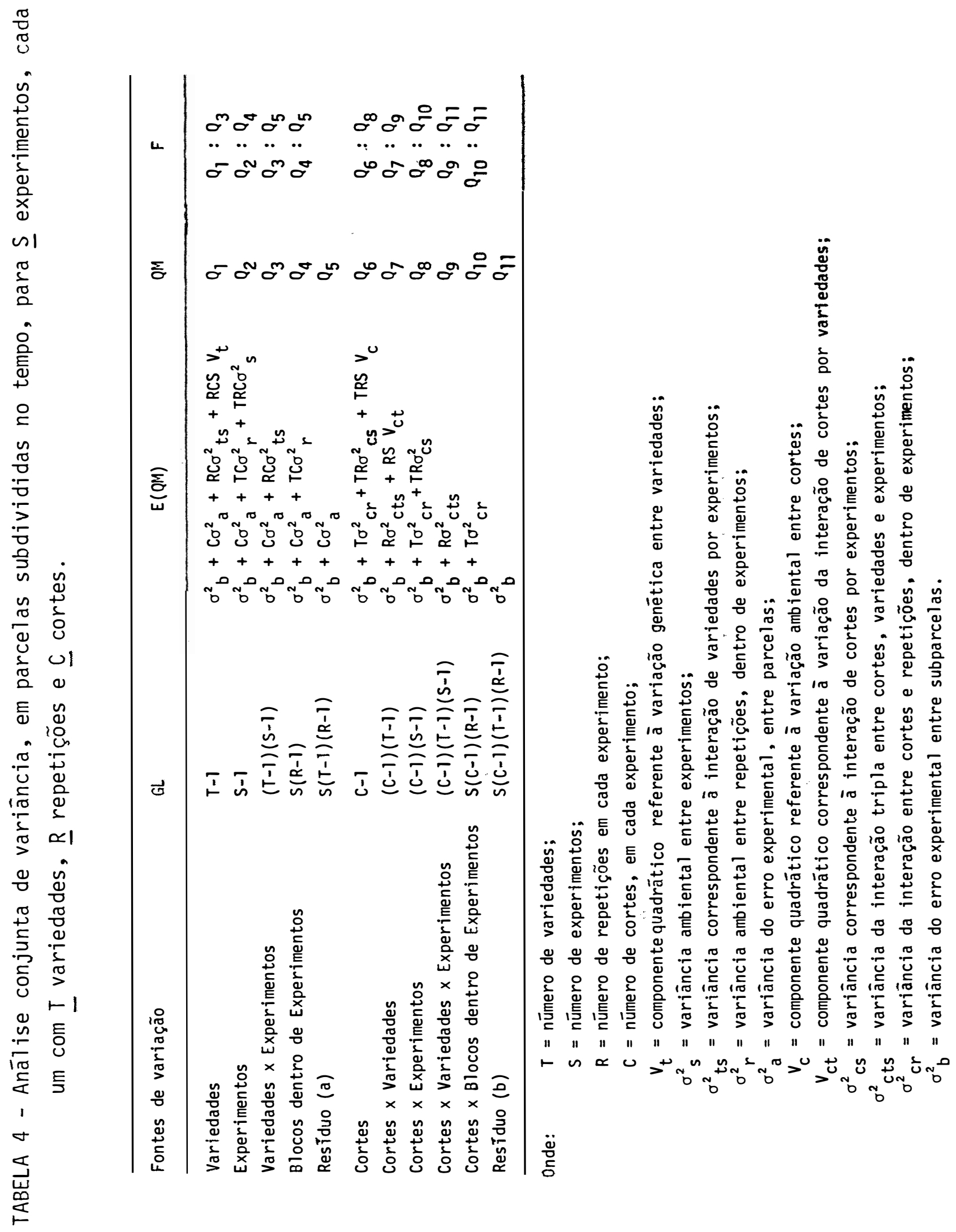


e como fixos os efeitos de variedades e cortes.

As estimativas dos parāmetros de estabilidade foram obtidas separadamente para cada corte e para os dois cor tes conjuntamente, considerados como ambientes diferentes. Utilizou-se o modelo proposto por EBERHART e RUSSEL (1966):

$$
\gamma_{i j}=\mu_{i}+\beta_{i} I_{j}+\delta_{i j}+\bar{\varepsilon}_{i j}
$$

onde:

$$
\begin{aligned}
Y_{i j}= & \text { média observada da variedade } \underline{i} \text { no ambiente } \\
& \underline{j} ; \\
\mu_{i}= & \text { média da variedade } \underline{i} \text { em todos os ambientes; } \\
\beta_{i}= & \text { coeficiente de regressão que mede a resposta } \\
& \text { da variedade } \underline{i} \text { à variação de ambientes; } \\
\delta_{i j}= & \text { desvio da regressão da variedade } \underline{i} \text { no am- } \\
& \text { biente } \underline{j} ; \\
I_{j}= & \text { indice ambiental dado pela diferença entre } \\
& \text { a produção média de cada ambiente com a pro } \\
& \text { dução média de todos os ambientes; } \\
\bar{\varepsilon}_{i j}= & \text { erro residual associado ã média. }
\end{aligned}
$$

A anālise de variāncia para estabilidade obede ceu ao modelo anterior e está apresentada de maneira semelhan te a BONATO (1978) e SANTOS (1980), na Tabela 5. Esta anālise permite decompor a soma dos quadrados de ambientes dentro de variedades nos efeitos lineares (ambiente linear e variedades 


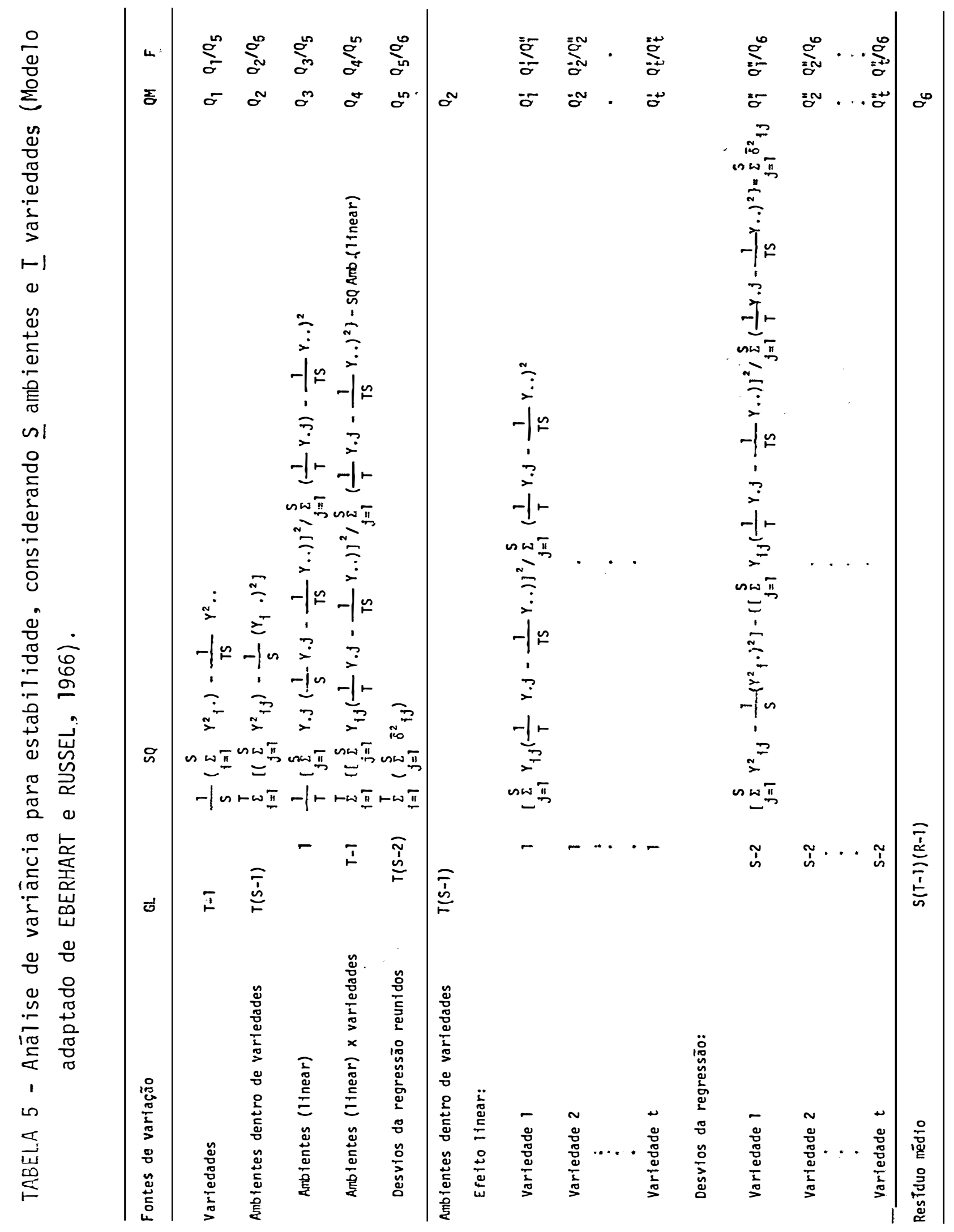


$x$ ambientes linear) e não-lineares (desvios da regressão), além de decompor a soma dos quadrados desses efeitos para cada variedade.

Durante a obtenção das anālises conjuntas, ava liou-se a homogeneidade dos quadrados médios residuais das análises individuais pelo teste de Bartlett (STEEL e TORRIE, 1960). Quando os quadrados médios residuais das anālises indi viduais em blocos casualizados mostraram-se heterogèneos, ajustaram-se os graus de liberdade do residuo e das interações através do método de Cochran, apresentado em PIMENTEL GOMES (1976). O mesmo procedimento foi empregado para as anālisesde estabilidade, com referéncia aos graus de liberdade dos "desvios da regressão" e dos "ambientes dentro de variedades". Na análise conjunta dos experimentos em parcelas subdivididas no tempo, o ajustamento dos graus de liberdade obedeceu a pro cesso apresentado por ZONTA (1978).

Estimou-se os coeficientes de regressão $\left(b_{i}\right)$, seus respectivos erros $s\left(b_{j}\right)$ e os coeficientes de determinações $\left(R^{2}\right)$ pelas seguintes expressões:

$$
b_{i}=\frac{\sum_{j=1}^{S} \bar{Y}_{i j}\left(\frac{1}{T} \bar{Y}_{. j}-\frac{1}{T S} \bar{Y}_{.} .\right)}{\sum_{j=1}^{S}\left(\frac{1}{T} \bar{Y}_{j}-\frac{1}{T S} \bar{Y} \ldots\right)^{2}}
$$




$$
\begin{aligned}
& s ( b _ { i } ) = 1 \longdiv { \frac { Q M \text { desvios da regressão de } ( t _ { i } ) } { \sum _ { j = 1 } ^ { S } ( \frac { T } { T } \overline { Y } \cdot j - \frac { T } { T S } \overline { Y } \ldots ) ^ { 2 } } } \\
& R_{i}^{2}=\frac{S Q \text { efeito linear de }\left(t_{i}\right)}{\text { SQ efeito linear }\left(t_{j}\right)+S Q \text { desvios da regressão }\left(t_{j}\right)}
\end{aligned}
$$

A hipótese de que os valores dos coeficientes de regressão linear, estimados, para cada variedade, não diferem da unidade, foi avaliada pelo teste t:

$$
t=\frac{b_{i}-1}{s\left(b_{i}\right)}
$$

onde:

$$
\begin{aligned}
\bar{Y}_{i j}= & \text { média da variedade } i \text { no ambiente } j ; \\
\bar{Y}_{. j}= & \text { média de todas as variedades no ambiente } j ; \\
\bar{Y}_{.}= & \text {média de todas as variedades em todos os ambien } \\
& \text { tes } ; \\
T= & \text { nūmero de variedades; } \\
S= & \text { nūmero de ambientes } \\
t_{i}= & \text { variedade } \underline{i} .
\end{aligned}
$$

A determinação da repetibilidade da produção mé 
dia, coeficiente de regressão e variāncia dos desvios da regressão $\left(s_{d_{j}}^{2}=Q^{\prime \prime}{ }_{i}\right.$ da Tabela 5 ) foram feitas separando-se as observações de cada experimento em dois grupos, onde as duas primeiras repetições formaram um grupo e as duas ūitimas formaram o outro. A partir das observações de cada grupo foram estimados os parámetros de estabilidade para cada variedade. As estimativas da variāncia dos desvios da regressão foram transformados para escala logarítmica. Em seguida realizou-se as anāitises de variāncia, em blocos casualizados, para cada parāmetro, onde cada grupo representava uma repetição. As esperanças matemāticas dos quadrados médios dessas anālises, en contram-se na Tabela 6 .

TABELA 6 - Anālise de variāncia em blocos ao acaso, considerando G grupos e $T$ variedades, para o estudo de repetibilidade.

Fontes de variāncia

QM

Grupos

G-1

Variedades

$T-1$

$(T-1)(G-1)$

$\sigma^{2}+G \sigma^{2} g$

$Q_{1}$

Residuo

$\sigma^{2}$

$Q_{2}$

onde:

$$
\begin{aligned}
& \bar{\sigma}^{2}=Q_{2} \\
& \bar{\sigma}_{g}^{2}=\frac{Q_{1}-Q_{2}}{G}
\end{aligned}
$$


A repetibilidade das produções médias, dos coe ficientes de regressão linear e das variāncias dos desvios da regressão, foi estimado de acordo com o apresentado por BONATO (1978)

onde: $\quad r_{i}=\frac{\bar{\sigma}_{g}^{2}}{\bar{\sigma}_{g}^{2}+\bar{\sigma}^{2}}$

A estimativa do erro associado à estimativa do coeficiente de repetibilidade $\left[s\left(r_{i}\right)\right]$ foi calculada utilizando-se a expressão seguinte, obtida pela metodologia de VELLO e VENCOVSKY (1978):

$$
s\left(r_{j}\right)=\sqrt{\frac{2[(T-1)+(T-1)(G-1)+4]}{[(T-1)+2][(T-1)(G-1)+2]}} \cdot \frac{G \cdot Q_{1} \cdot Q_{2}}{\left[Q_{1}+(G-1) Q_{2}\right]^{2}}
$$


4. RESULTADOS

As produções mēdias das variedades, média geral, variāncias residuais e os coeficientes de variação experimental dos 29 experimentos são apresentados nos Apēndices 1 e 2, respectivamente para o primeiro e segundo cortes. As pro duções superiores no primeiro e segundo cortes, respectivamen te de 102,66 ( $\mathrm{TCH})$ e $90,00(\mathrm{TCH})$, foram obtidas no experimento nọ 20, instalado na Usina Central 01ho D'Água, em 1973, enquanto as produções inferiores 48,43 (TCH) e 30,50 (TCH) cor respondem aos experimentos nọ 27, instalado na Usina Estivas, em 1974 e o experimento nọ 17, instalado na Usina Central Bar reiros em 1973. Estes limites indicam haver uma ampla variação ambiental na Coordenadoria Regional Norte do IAA - PLANALSUCAR (Nordeste Brasileiro). Tal fato justifica plenamente um estudo de estabilidade fenotípica. Os coeficientes de variação oscilaram de $6,66 \%$ a $18,88 \%$ no primeiro corte e de $7,13 \%$ a $26,42 \%$ no segundo corte. 
Encontraram-se diferenças estatisticamente sig nificativas entre variedades, experimentos e para a interação variedades $x$ experimentos nas anāijises conjuntas em blocos ca sualizados, dos 29 experimentos, considerando cada corte sepa radamente (Tabela 7 ). Estes resultados indicam que os experimentos (locais e anos) devem ser considerados ambientes contrastantes no estudo de estabilidade.

A Tabela 8 fornece o resultado da anāilise conjunta de variáncia dos experimentos em parcelas subdivididas no tempo, onde as variedades formam as parcelas e cortes formam as subparcelas. A significáncia dos quadrados médios, atravēs do teste $F$, para "cortes, cortes x variedades, cortes $x$ experimentos, cortes $x$ variedades $x$ experimentos", indicam que, alēm de locais e anos, os cortes tambēm representam ambientes contrastantes e como tal devem ser considerados no es tudo de estabilidade.

As anālises de variāncia para estabilidade, re ferentes aos 29 ambientes do primeiro corte, aos 29 ambientes do segundo e ao total de 58 ambientes (primeiro e segundo cor tes), estão apresentados nas Tabelas 9,10 e 11. Observa - se nestas anāijses similaridades nas informações, pois em todas elas foram detectadas diferenças significativas para "ambientes dentro de variedades" para seus desdobramentos em efeitos lineares (ambiente linear e ambiente linear x variedades) e não-lineares (desvios da regressão reunidos). A decomposição dos efeitos lineares e não lineares para cada variedade tam- 
TABELA 7 - Anālises conjuntas da variāncia em blocos casualizados de 29 experimentos, com seis variedades de cana-de-açúcar, e quatro repetições, considerando o primeiro e segundo cortes separadamente

\begin{tabular}{|c|c|c|c|c|}
\hline \multirow{2}{*}{ Fontes de variação } & \multicolumn{2}{|c|}{ Primeiro Corte } & \multicolumn{2}{|c|}{ Segundo Corte } \\
\hline & GL & QM & GL & QM \\
\hline Variedades & 5 & $11.191,65 \star \star$ & 5 & $7.269,86 \star \star$ \\
\hline Experimentos & 28 & $4.809,83 \star \star$ & 28 & $5.778,51 * \star$ \\
\hline Variedades $x$ Experimentos & $140(51)$ a & $524,73 * \star$ & $140(76)$ a & $214,92^{\star \star}$ \\
\hline $\begin{array}{c}\text { Blocos dentro de } \\
\text { Experimentos }\end{array}$ & 87 & 238,47 & 87 & 142,74 \\
\hline Resĩduo & $431(303)$ a & ! 93,86 & $430(387)$ - $/$ & 60,04 \\
\hline
\end{tabular}

** Significativo ao nível de $1 \%$.

af Graus de liberdade ajustados.

bém mostrou significância estatística para as variāncias. Entretanto, as magnitudes das variāncias não se mostraram consistentes de um corte para outro, como também não apresentaram a mesma ordenação. No primeiro corte a variedade CB45-3 a presentou a maior variáncia $(12.143,56)$ para efeito linear das variedades e a menor variāncia $(62,72)$ para os desvios da regressão, enquanto que para a variedade CP53-76 observou-se o contrário, ou seja, menor variāncia $(1.806,75)$ do efeito linear e maior variáncia $(151,07)$ dos desvios da regressão. No segundo corte, a variedade CB61-27 apresentou a maior variāncia $(10.622,48)$ do efeito 1 inear, enquanto a variedade CP51-22 apresentou, a menor variāncia $(2.964,51)$, tanto para o efeito 
TABELA 8 - Anālise conjunta de variāncia em parcelas subdivididas no tempo, de 29 experimentos, com seis variedades, quatro repetições dois cortes.

Fontes de variação

$G L$

QM

Variedades

5

$17.927,39 * *$

Experimentos

28

Variedades $x$ Experimentos

$140(121)$ a $/$

$5.399,74 * \star$

Blocos dentro de Experimentos

87

Resĩduo (a)

$431(375)$ a $/$

$519,79 * *$

255,73

86,33

Cortes

Cortes $x$ Variedades

Cortes $x$ Experimentos

Cortes $x$ Variedades $x$ Experimentos

Cortes $\times$ Blocos dentro de Experimentos

Residuo (b)

\section{1}

5

$28(19)$ a/

$140(95)$ al

87

$430(347)$ a
$78.528,17 * \star$

$534,21 *$

$5.188,65 * *$

$219,86 * *$

125,35

\footnotetext{
* Significativo a $5 \%$.

** Significativo a $1 \%$.

a/ Graus de liberdade ajustados.
}

linear, como para os desvios da regressão $(27,88)$ e a varieda de CP53-76 continuou apresentando a maior variāncia dos desvios da regressão.

As produções médias ( $T C H)$, os coeficientes de regressão (b), as variāncias dos desvios da regressão ( $s_{d}^{2}$ ) e os coeficientes de determinação das seis variedades estudadas, obtidos a partir do total de 58 ambientes estão apresentados na Tabela 12. O comportamento médio destas variedades 
TABELA 9 - Anālise de variāncia da producção média de colmos de seis varie dades de cana-de-açúcar, considerando os 29 ambientes do primeiro corte (modelo adaptado de EBERHART e RUSSEL, 1966).

\begin{tabular}{|c|c|c|c|}
\hline Fontes de variação & GL & QM & $\mathrm{F}$ \\
\hline Variedades & 5 & $2.797,91$ & $119,11 * \star$ \\
\hline Ambientes dentro de Variedades & 168 & 309,72 & $13,19 * \star$ \\
\hline Ambientes (1 inear) & 1 & $33.782,93$ & $354,90 * \star$ \\
\hline Ambientes (1 inear) $\times$ Variedades & 5 & 565,97 & $5,95 * \star$ \\
\hline Desvios da regressão reunidos & 162 & 95,19 & $4,05 * \star$ \\
\hline Resĩduo médio & $431(303)$ a & 23,49 & \\
\hline \multicolumn{4}{|l|}{ Ambientes dentro de Variedades } \\
\hline CB45-3 & 1 & $12.143,56$ & $193,62 \star \star$ \\
\hline CB47-355 & 1 & $5.872,68$ & $85,65^{\star \star}$ \\
\hline CB55-18 & 1 & $3.897,88$ & $46,28 * *$ \\
\hline CB61-27 & 1 & $8.491,84$ & $114,80 * \star$ \\
\hline CP51-22 & 1 & $4.400,09$ & $33,69 * *$ \\
\hline CP53-76 & 1 & $1.806,75$ & $11,96 * *$ \\
\hline \multicolumn{4}{|l|}{ Desvios da regressão das variedades } \\
\hline CB45-3 & 27 & 62,72 & $2,67 \star \star$ \\
\hline CB47-355 & 27 & 68,57 & $2,92 * \star$ \\
\hline CB55-18 & 27 & 84,22 & $3,59 * \star$ \\
\hline CB61-27 & 27 & 73,97 & $3,15^{\star \star}$ \\
\hline CP51-22 & 27 & 130,59 & 5,56 ** \\
\hline CP53-76 & 27 & 151,07 & $6,43 * \star$ \\
\hline Resĩduo médio & $431(303) \frac{a}{-}$ & 23,49 & \\
\hline
\end{tabular}

** Significativo a $1 \%$.

a/ Graus de liberdade ajustados. 
TABELA 10 - Anālise de variāncia da produção média de colmos de seis variedades de cana-de-açūcar, considerando os 29 ambientes do segundo corte (modelo adaptado de EBERHART e RUSSEL, 1966).

\begin{tabular}{|c|c|c|c|}
\hline Fontes de variação & $\mathrm{GL}$ & QM & $\mathrm{F}$ \\
\hline Variedades & 5 & $1.817,47$ & $121,08 * \star$ \\
\hline Ambientes dentro de variedades & 168 & 285,26 & $19,01 * \star$ \\
\hline Ambientes (1 inear) & 1 & $40.419,97$ & $1.050,96 * *$ \\
\hline Ambientes (1 inear) x variedades & 5 & 254,60 & $6,62 * \star$ \\
\hline Desvios da regressão reunidos & 162 & 38,46 & 2,56 ** \\
\hline Resîduo médio & $430(387) \underline{a /}$ & 15,01 & \\
\hline
\end{tabular}

Ambientes dentro de Variedades 168

Efeito linear das variedades

\begin{tabular}{|c|c|c|c|}
\hline CB45-3 & 1 & $6.844,83$ & $180,89 * \star$ \\
\hline CB47-355 & 1 & $8.154,08$ & $234,45^{\star \star}$ \\
\hline CB55-18 & 1 & $6.531,87$ & $223,08 * \star$ \\
\hline CB61-27 & 1 & $10.622,48$ & 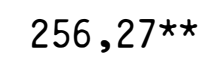 \\
\hline CP51-22 & 1 & $2.964,51$ & $106,33 * \star$ \\
\hline СР53-76 & 1 & $6.575,18$ & $110,41^{\star *}$ \\
\hline
\end{tabular}

Desvios da regressão das variedades

\begin{tabular}{lccc} 
CB45-3 & 27 & 37,84 & $2,52 \star \star$ \\
CB47-355 & 27 & 34,78 & $2,32 \star \star$ \\
CB55-18 & 27 & 29,28 & $1,95^{\star \star}$ \\
CB61-27 & 27 & 41,45 & $2,76 \star \star$ \\
CP51-22 & 27 & 27,88 & $1,86 \star \star$ \\
CP53-76 & 27 & 59,55 & $3,97 \star \star$ \\
\hline Resíduo médio & $430(387)$ a/ & 15,01 & \\
\hline
\end{tabular}

** Significativo ao nivel de $1 \%$.

a/ Graus de liberdade ajustados. 
TABELA 11 - Anālise de variância da produção média de colmos de seis va riedades de cana-de-açūcar, considerando o total de 58 ambien tes de dois cortes (modelo adaptado de EBERHART e RUSSEL, 1966).

\begin{tabular}{|c|c|c|c|}
\hline Fontes de variação & GL & QM & $\mathrm{F}$ \\
\hline Variedades & 5 & $4.481,85$ & $232,70 * \star$ \\
\hline Ambientes dentro de variedades 3 & 342 & 351,66 & $18,26 * \star$ \\
\hline Ambientes ( 1 inear) & 1 & $93.615,98$ & $1.319,09 * *$ \\
\hline Ambientes ( 1 inear) $x$ variedades & 5 & 561,66 & $7,91 * \star$ \\
\hline Desvios da regressão reunidos & $336(309)$ a & 70,97 & 3,68 \\
\hline Resĩduo médio & $861(614)$ a $/$ & 19,26 & \\
\hline \multicolumn{4}{|l|}{ Ambientes dentro de variedades } \\
\hline \multicolumn{4}{|l|}{ Efeito linear das variedades } \\
\hline CB45-3 & 1 & $23.929,33$ & $387,58^{* \star}$ \\
\hline CB47-355 & 1 & $17.493,04$ & $343,27 * \star$ \\
\hline CB55-18 & 1 & $12.963,70$ & $229,20 * \star$ \\
\hline CB61-27 & 1 & $21.854,47$ & $361,41 * \star$ \\
\hline CP51-22 & 1 & $10.693,60$ & $127,24 * \star$ \\
\hline CP53-76 & 1 & $9.489,63$ & $84,71 * \star$ \\
\hline \multicolumn{4}{|c|}{ Desvios da regressão das variedades } \\
\hline CB45-3 & 56 & 61,74 & $3,21 * *$ \\
\hline CB47-355 & 56 & 50,96 & $2,65^{\star \star}$ \\
\hline CB55-18 & 56 & 56,56 & $2,94 \star \star$ \\
\hline CB61-27 & 56 & 60,47 & $3,14 \star \star$ \\
\hline CP51-22 & 56 & 84,04 & $4,36 * \star$ \\
\hline CP53-76 & 56 & 112,02 & $5,82 \star \star$ \\
\hline Resĩduo médio & $61(614)$ a/ & 19,26 & \\
\hline
\end{tabular}

** Significativo a $1 \%$.

a/ Graus de liberdade ajustados. 
TABELA 12 - -Produções médias (TCH), coeficientes de regressão (b), va riāncia dos desvios $\left(s_{d}^{2}\right)$ e coeficientes de determinação $\left(R^{2}\right)$ de seis variedades de cana-de-açūcar, considerando 58 ambientes (29 experimentos de cada corte).

\begin{tabular}{|c|c|c|c|c|c|}
\hline Variedades & $\mathrm{TCH}$ & $\%$ & $b \pm s(b)$ & $s_{d}^{2}$ & $\mathrm{R}^{2}(\%)$ \\
\hline CB45-3 & 79,04 & 14,62 & $1,24 \pm 0,06$ & 61,74 & 87,38 \\
\hline CB47-355 & 67,29 & 97,58 & $1,06 \pm 0,06$ & 50,96 & 85,97 \\
\hline CB55-18 & 58,42 & 84,72 & $0,91 \pm 0,06$ & 56,56 & 80,36 \\
\hline CB 61-27 & 79,90 & 115,86 & $1,18 \pm 0,06$ & 60,47 & 86,58 \\
\hline CP51-22 & 67,09 & 97,29 & $0,83 \pm 0,07$ & 84,04 & 69,44 \\
\hline CP53-76 & 62,00 & 89,91 & $0,78 \pm 0,08$ & 112,02 & 60,20 \\
\hline Mēdia & 68,96 & 100,00 & 1,00 & 70,97 & 80,17 \\
\hline
\end{tabular}

foi relativamente contrastante $(58,42 \mathrm{TCH}$ para a variedade CB55-18 a 49,90 TCH para (B61-27), corroborando as indicações das anālises de variāncia de que existe variação genētica entre variedades. Os coeficientes de regressão linear oscilaram de 0,78 (CP53-76) a 1,24 (CB45-3) o que mostra um contraste quanto à adaptação das variedades. As variāncias dos desvios da regressão ( $s_{d}^{2}$ ) também oscilaram de 50,96 (CB47-355) a 112,02 $(C P 56-76)$.

A Tabela 13 mostra as estimativas dos parâmetros, produção média $(T C H)$, coeficiente de regressão linear 


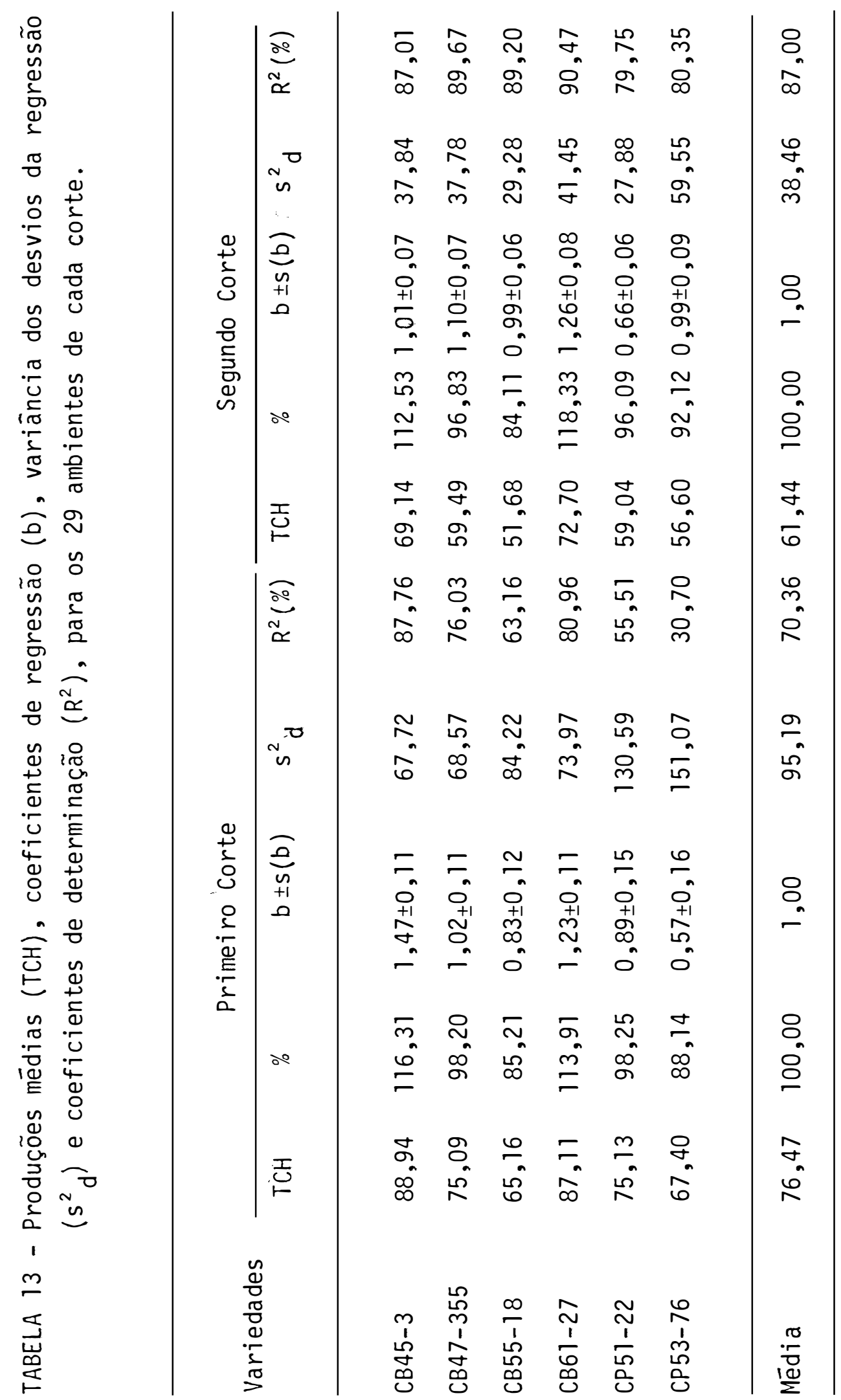


$\left(b_{j}\right)$, variāncia dos desvios da regressão $\left(s_{d}^{2}\right)$ e coeficientes de determinação das seis variedades, obtidos considerando-se os 29 ambientes do primeiro e do segundo cortes, respectiva mente. A comparação das produções médias das variedades mostrou diferenças acentuadas nas suas magnitudes, e ordenações diferentes. Este fato, se repete para os coeficientes de regressão linear e para a variāncia dos desvios da regressão, de um corte para outro, o que indica que a avaliação da estabili dade fenotipica das variedades é mais precisa quando se cons dera o total de 58 ambientes (os dois cortes).

As produções médias de colmos em TCH, os coefi cientes de regressão linear (b) e as variāncias dos desvios da regressão $\left(s_{d}^{2}\right)$ para os grupos I e II, correspondentes às combinações das duas primeiras repetições $\left(R_{1} R_{2}\right)$ e das duas ūiti mas $\left(R_{3} R_{4}\right)$ estão apresentados no Apēndice 3 . As anālises de va riāncia em blocos casualizados, considerando cada grupo, uma repetição, as estimativas da variāncia genética $\left(\sigma_{\mathrm{g}}^{2}\right)$, variāncia do erro $\left(\bar{\sigma}^{2}\right)$ e dos coeficientes de repetibilidade para ca da parāmetro, são fornecidos nas Tabelas 14,15 e 16.

os coeficientes de repetibilidade para produção, revelaram-se os mais altos $(>0,96)$ e foram semelhantes para cada corte individualmente e para os dois cortes conjuntos. As repetibilidades para os coeficientes de regressão (b) também mostraram valores altos (em torno de 0,80 ) e semelhantes de um corte para outro, embora no geral tenham sido mais baixos do que a repetibilidade da produção. Já os valores de 


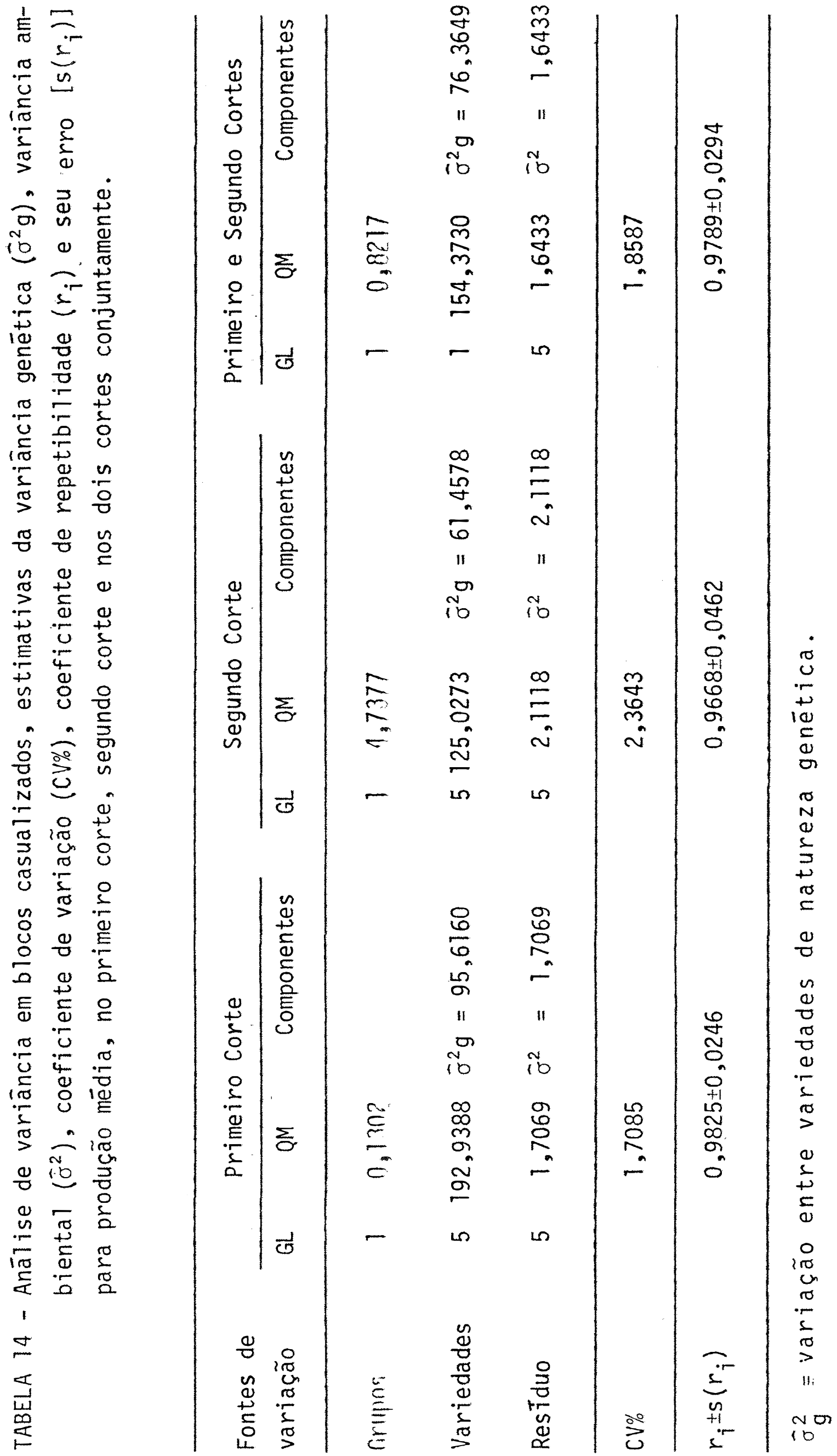




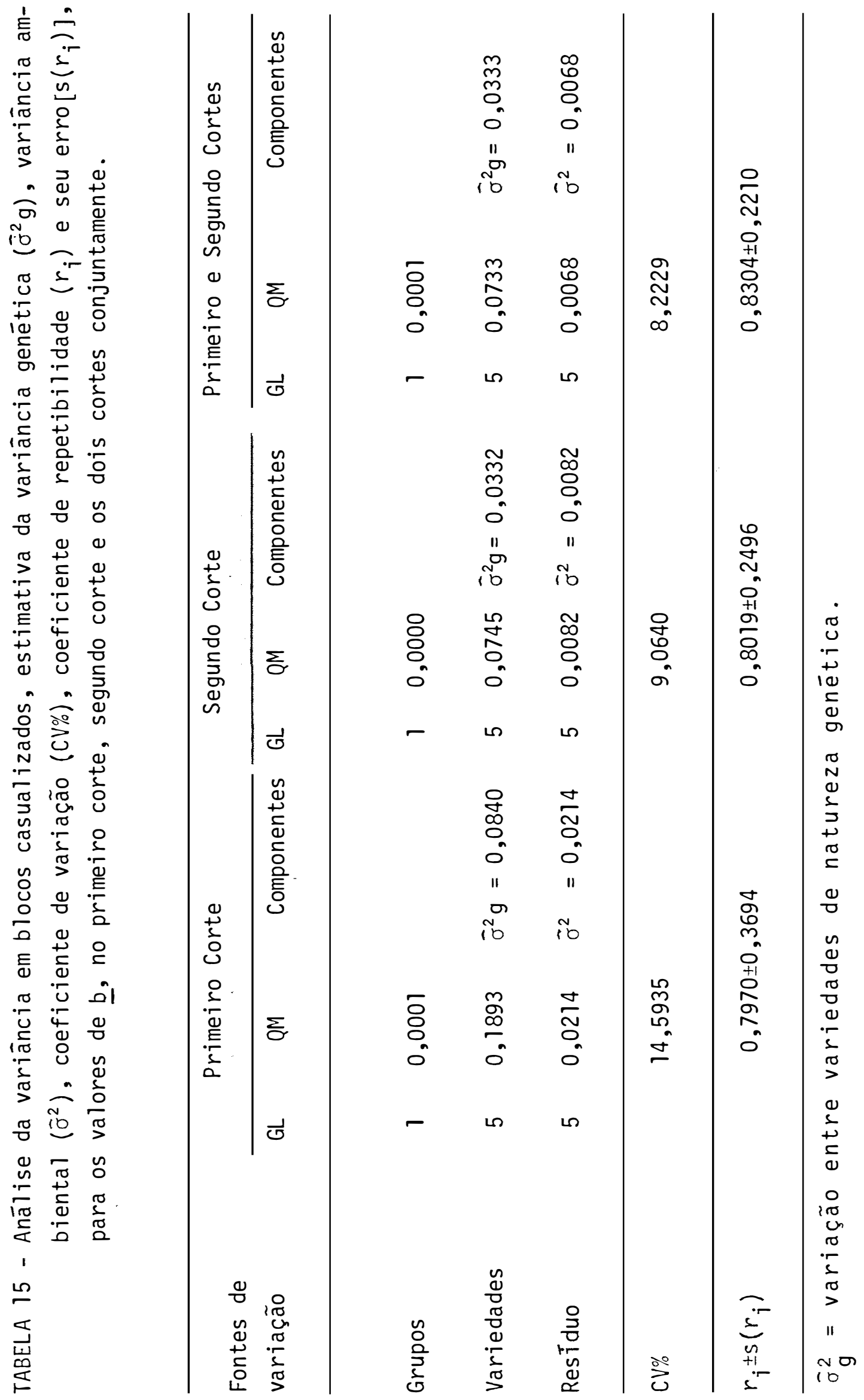


40.

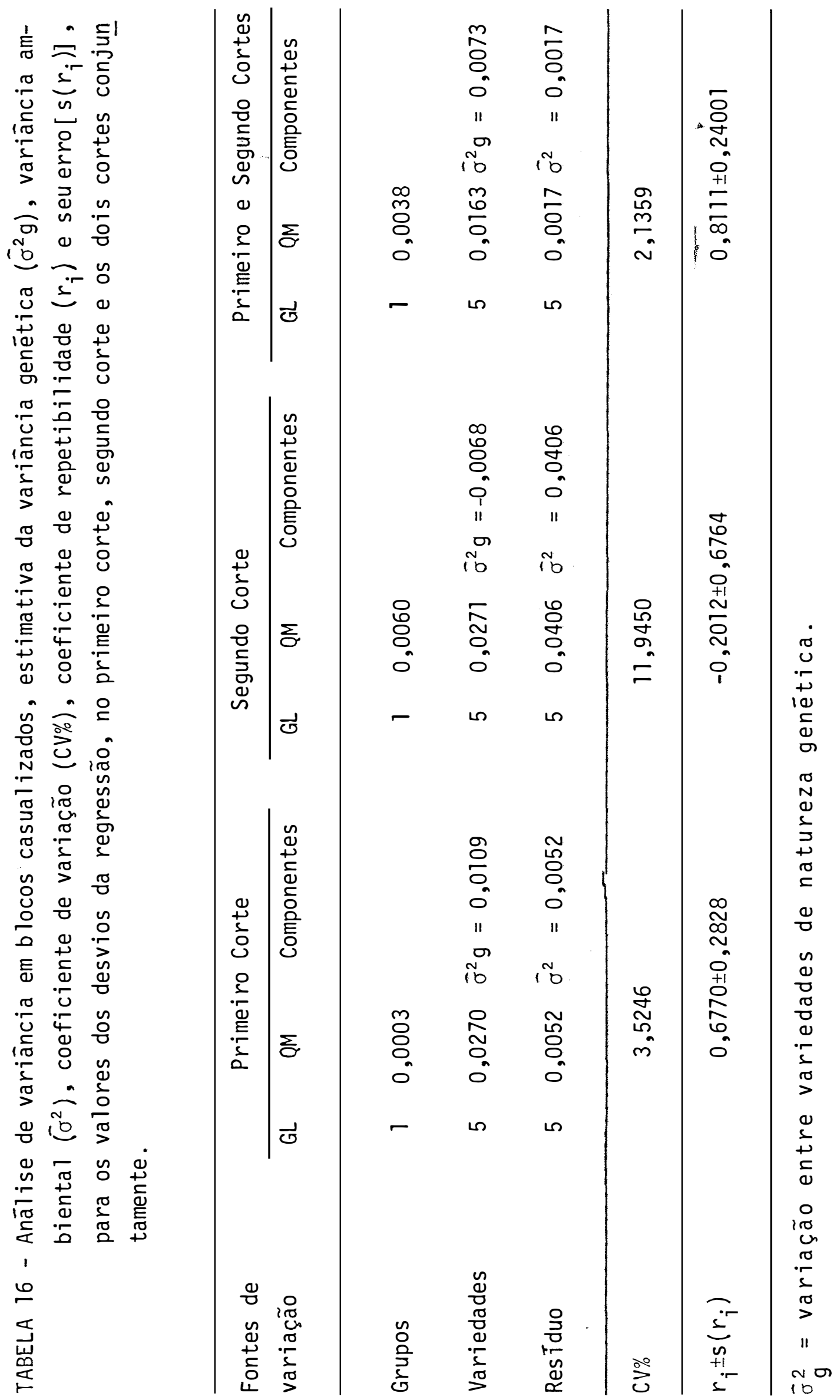


- repetibilidade da variância dos desvios da linearidade ( $s_{d}^{2}$ ) os cilaram muito de um para outro corte: 0,6770 para o primeiro corte, $-0,2012$ para o segundo corte e 0,8111 para os dois cortes conjuntos. 


\section{DISCUSSÃO}

\subsection{Considerações Gerais}

Num programa de melhoramento da cana-de-açūcar, os clones gerados pela recombinação genética, assim como, as variedades introduzidas, passam por uma sērie de etapas de se leção, sendo os eleitos testados em experimentos de competição como uma ūltima fase de seleção. Estes experimentos são normalmente conduzidos em vários locais e anos. Os dados obti dos nestes experimentos tornam possível analisar a estabilida de das variedades envolvidas.

Estudos de estabilidade fenotípica das varieda des são ūteis aos melhoristas, pois permitem sintetizar em poucos parāmetros o enorme volume de informações obtidas num grande número de experimentos distribuídos por locais e anos agrícolas diferentes. Esta técnica se aplica com extrema efi- 
ciēncia aos programas de melhoramento desenvolvidos pelos Ins tituto do Açūcar e do Álcool (IAA), através do Programa Nacio na l: do Melhoramento da Cana-de-Açūcar (PLANALSUCAR), que tem na sua rotina de trabalho um grande número de experimentos, em função da ampla variação ambiental existente nas regiões cana vieiras do Brasil.

Os experimentos utilizados neste estudo, foram instalados em sete locais e très anos, sendo uma amostra representativa da ārea Canavieira da Coordenadoria Regional Nor te, do IAA-PLANALSUCAR, que no periodo mencionado desenvolvia um programa de melhoramento para os Estados de Pernambuco, Pa rába e Rio Grande do Norte. Entretanto, atualmente, esta área foi ampliada até o extremo Norte, com a finalidade de atender às necessidades técnicas oriundas da expansão da cultú ra em função do Programa Nacional do Alcool.

Estas novas āreas apresentam diferenças marcan tes em fatores climáticos e edáficos, de maneira a provocar mudanças evidentes no cultivo da cana-de-açūcar, tais como di ferentes épocas de plantio e colheita. Em muitos casos, tais mudanças chegam a alterar o ciclo da cultura. Desta forma, é mais seguro limitar a aplicação dos resultados deste estudo aos très Estados iniciais.

As diferenças entre as médias de produção dos experimentos (Apēndices 1 e 2 , pāgs. 67 e 68) são explicados por diferenças de condições climáticas, edáficas, épocas de plantio e colheita e tratos culturais existentes entre os ex- 
perimentos. A variação existente entre médias de experimentos e entre médias de variedades é responsável pelas interações significativas entre variedades e ambientes (locais, anos e cortes). Tal situação é especialmente adequada para aplicação da técnica da regressão na avaliação do comportamento das variedades. A escolha do modelo de EBERHART e RUSSEL 91966) para estudar a estabilidade fenotípica das variedades baseou se nos resultados comparativos de KALTSIKES e LATER (1970), J0 WETT (1972), EASTON e CLEMENTS (1973), OLIVEIRA (1976) e GALVEZ (1980).

\subsection{Caracterização de Ambientes}

A importāncia da presença da interação de genō tipos por ambientes em programas de melhoramento de plantas tem sido objetivo de muitos trabalhos, que comprovam a interferēncia deste parāmetro nos progressos genéticos alcançados na seleção e nas recomendações de variedades para uma amplitú de de ambientes. Na cultura da cana-de-açúcar a presença de in terações de variedades por ambientes também tem sido comprova da por GEORGE (1963), MARIOTTI (1974), ESPINOZA e GALVEZ (1980), e outros autores que mostram o aparecimento de interações do tipo Variedades $x$ Locais, Variedades x Anos, Variedades x Cor tes, Variedades $x$ Epocas de plantio e Variedades $x$ Epocas de cortes. 
No presente estudo a caracterização de ambientes para o estudo de estabilidade foi feita através das anāli ses conjuntas de variāncias em blocos casualizados para cada corte separadamente e pela anālise conjunta de variāncia em parcelas subdivididas no tempo (STEEL e TORRIE, 1960). Nas duas anālises conjuntas de variāncias em blocos casualizados a significāncia da interação de Variedades x Experimentos (Tá bela 7, pág. 30), permitiu considerar nas anālises de estabilidade para cada corte, experimentos como ambientes diferentes. A anālise conjunta de variāncia em parcelas subdivididos no tempo (Tabela 8, pág. 31), permitiu atravēs da significāncia das interações "Variedades x Cortes" e "Variedades x Cortes x Experimentos", considerar cada corte de cada experimento como um ambiente diferente.

Dessa forma, locais, anos agrícolas e cortes são considerados ambientes e, conseqüentemente, a estabilidade fenotípica das variedades é avaliada para esta ampla faixa de variação ambiental. Colheitas sucessivas tambēm foram consideradas como ambientes diferentes por BREESE (1969), HILL e SAMUEL (1971) em gramineas forrageiras e por MONTEIRO (1975) em berinjela.

\subsection{Avaliação da Estabilidade Fenotípica}

Da anālise de variāncia para estabilidade (Tabela 11, pāg. 34), verifica-se que os efeitos lineares são 
1327 vezes superiores aos efeitos não-lineares, indicando que a maior parte da variação de ambientes dentro de variedades é explicada pela regressão linear, correspondendo a um coeficiente de determinação de $80,27 \%$ da variação total de ambientes dentro de variedades. Estes resultados concordam com o en contrado por MARIOTTI et alii (1976) e GALVEZ (1980) na cultú ra da cana-de-açūcar e com os resultados encontrados em outras culturas por BUCIO ALANIS (1966), BREESE (1969), PERKINS e JINKIS (1971), BILBRO e RAY (1976), BONATO (1978) e SANTOS (1980) .

A significāncia estatística da interação de am bientes linear $x$ variedades revelou a existenciade diferenças genéticas entre as variedades para seus comportamentos lineares frente às variações ambientais. Desta maneira, os coeficientes de regressão linear constituem-se em parâmetros ūteis para diferenciar a adaptação dessas variedades em um ambiente determinado, além de serem ūteis na predição de suas respostas frente à amplitude dos ambientes considerados. Tal fato concorda com o resultado obtido na cultura do feijão por SANTOS $(1980)$.

As diferenças nas variāncias dos desvios da re gressão reunidos representam diferenças genēticas entre as va riedades, indicando que existem diferenças quanto às suas estabilidades, ou seja, quanto à predição de seus comportamentos em ambientes particulares.

A decomposição dos efeitos lineares e não-1i- 
neares para cada variedade (segunda parte da Tabela 11, pág. 34), permitiu caracterizar o quanto da variação de cada varie dade pode ser explicada em termos de regressão linear e seus desvios.

0 quociente entre as variāncias do efeito linear e dos desvios da linearidade para cada variedade (Tabela 11, pāg. 34), foi superior para a variedade CB45-3 (F=387,59) e inferior para a variedade $\operatorname{CP53-76}(F=84,71)$, indicando exis tir diferenças entre as variedades quando ao tipo de resposta à variação ambiental. o coeficiente de determinação, corrobo rando com esta informação (Tabela 12, pāg. 35), mostra que o efeito linear para a variedade CB45-3 é responsāvel por $87,38 \%$ da variação e para a variedade CP53-76 por apenas $60,20 \%$. Ap sar da significāncia dos efeitos lineares para todas as varie dades e a sua predomināncia sobre os efeitos não-lineares, e tes $\bar{u}$ timos tambēm se apresentaram significativos, indicando a possibilidade de comportamentos imprevisíveis em ambientes particulares.

Os coeficientes de regressão apresentados na Tá bela 12, pāg. 35) mostram o maior valor $(b=1,24)$ para a variedade CB 45-3, indicando maior capacidade desta variedade em responder aos estímulos ambientais favoráveis. 0 menor valor do coeficiente de regressão linear $(b=0,78)$ obtido para a variedade CP53-76, indica que esta variedade apresenta adaptação maior aos ambientes de baixa capacidade de produção. Apenas as variedades $\operatorname{CB} 47-355(b=1,06)$ e $\operatorname{CB} 55-18(b=0,91)$ ti 
veram coeficientes de regressão linear semelhantes à unidade, atravēs do Teste t. Este comportamento diferencial das variedades jā era esperado com base na significāncia da interação de ambientes linear $x$ variedades.

EBERHART e RUSSEL (1966), consideram uma culti var estável quando apresenta $b=1 \mathrm{e} \mathrm{s}_{\mathrm{d}}^{2}=0$ (zero). Esse conceito significa que uma cultivar estável é aquela que apresenta respostas progressivas e previsiveis aos melhoramentos ambientais. Os autores estabeleceram estes conceitos para as cul turas cujo sistema de produção utiliza uma tecnologia moderna. Isto é o que tem acontecido com a agricultura atual, que está sempre se desenvolvendo no sentido de aumentar a produtividade para atender às necessidades do consumo.

Quando o coeficiente de regressão linear de uma variedade é superior a unidade $(b>1)$, significa que a mes ma responde positivamente às melhorias ambientais, no entanto, em condições desfavoráveis, este comportamento pode ser bas tante prejudicado. Por outro Tado, quando o coeficiente de re gressão linear de uma variedade for inferior a unidade $(b<1)$, esta não responde satisfatoriamente às melhorias ambientais, mas tambēm não sofre prejuĩzos sērios em condições desfavorāveis.

A variāncia dos desvios da regressão quando baixa, indica que uma variedade em ambientes semelhantes deve apresentar comportamentos semelhantes. No entanto, quando a variāncia dos desvios da regressão for alta, a variedade não 
deve apresentar o mesmo comportamento em ambientes semelhan tes. Portanto, este parāmetro é de fundamental importāncia na avaliação da estabilidade fenotípica. Dentro dessas colocações é fācil perceber que uma variedade pode ser considerada estāvel com qualquer valor de b, desde que a variāncia dos des vios da linearidade seja nula. E importante salientar que tan to os valores de $\underline{b}$. como os da variāncia dos desvios da regres são sō serão de utilidade nas recomendações de variedades quan to estiverem associados a altas produções médias das respecti vas variedades.

Adotando este critērio e considerando que os va lores de b e das variāncias dos desvios da regressão (s ${ }_{d}^{2}$ ) para cada variedade são valores relativos, a avaliação da estabilidade fenotípica das variedades estudadas deve ser discuti da em termos comparativos, dentro do conjunto de variedades em estudo.

De acordo com a Tabela 12 (pāg. 35), a varieda de CB61-27 apresentou o maior potencial produtivo, tendéncia de resposta positiva às melhorias ambientais (b = 1,18; signi ficativamente superior à unidade) e variāncia dos desvios da linearidade significativa, mas com magnitude inferior à média geral das variáncias. No entanto, esta variedade tem contra si dois aspectos importantes. O primeiro deles se refere às características industriais, apresentando baixos percentuais de sacarose e maturação tardia. O segundo fator negativo compreende sua suscetibilidade $\bar{a}$ escaldadura da folha, doença cau 
sada pela bactēria Xanthomonas albilineans (Ashby) Dowson, con siderada das mais importantes no Nordeste.

Já as variedades CB47-355 e CB55-18 apresentam valores de b s'emelhantes à unidade e as menores variāncias dos desvios da linearidade. Todavia, ambas as variedades apresentam produções inferiores à produção média das seis variedades estudadas.

Ainda na Tabela 12 (pág. 35), observa-se que as variedades CP51-22 e CP53-76, procedentes de Canal Point (Fló rida, EUA), apresentam tendēncias de adaptação às condições ambientais menos favoráveis $(b<1)$. Além disso, elas mostraram comportamento dos mais imprevisiveis, em função de terem apre sentado as maiores variáncias dos desvios da linearidade.

Finalmente, a variedade CB45-3 mostrou capacidade produtiva satisfatória $(79,04 \mathrm{TCH})$, muito semelhante à variedade mais produtiva (CB61-27 com 79,90 TCH), potencial de resposta positiva aos estímulos ambientais $(b>1)$ e variāncia dos desvios da linearidade significativa mas inferior à média das variancias de todas as variedades estudadas. Esta varieda de é muito conhecida pela sua capacidade de adaptação, mostrando sempre uma produção que a situa entre as melhores variedades nas diversas regiões canavieiras do Brasil. Aparente mente, a tendéncia experimental da variedade CB45-3 em se adaptar melhor aos ambientes mais favoráveis (b>1) está em desacordo com seu comportamento em cultivos comerciais. Em primeiro lugar deve-se considerar que o parāmetro b tem valor re 
lativo, dependente das demais variedades que entraram nos ensaios. De fato, para um outro conjunto de variedades, RUSCHEL (1977) encontrou valor de b semelhante à unidade para a variedade CB45-3. Em segundo lugar, deve-se considerar as estimativas de b obtidas individualmente nos dois cortes (Tabela 13, pág. 36). A variedade CB45-3 apresentou valores de b iguais a 1,47 e 1,01, respectivamente para o primeiro e segun do cortes. No caso desta tendéncia permanecer num terceiro cor te, é de se esperar que para um conjunto de trēs cortes, prātica normal em cultivos comerciais, o valor de b da variedade CB45-3 se aproxime da unidade.

As Figuras 1 (pāg. 52) e 2 (pāg. 53) ilustram bem os diferentes comportamentos das seis variedades estuda das, frente às variações ambientais.

As anāitises realizadas para cada corte separadamente (Tabelas 9, pāg. 31 e 10, pāg. 32) confirmam a predomināncia dos efeitos lineares sobre os não-lineares. Entretan to, quando se compara o primeiro corte com os segundo, atravēs dos valores obtidos pelo quociente ( $F=$ variāncia dos efeitos lineares/variāncia dos efeitos não-lineares) verificase que o segundo corte tende a ser mais estável, o que confir ma os resultados obtidos por MARIOTTI et alii (1976). Também, não houve uma mesma ordenação das variedades de um corte para outro, o que confirma a significāncia das interações "varieda des x cortes" e "variedades x cortes $x$ experimentos", obtidas na Tabela 8 (pāg. 31). Os coeficientes de regressão linear de 
$5 \hat{2}$.

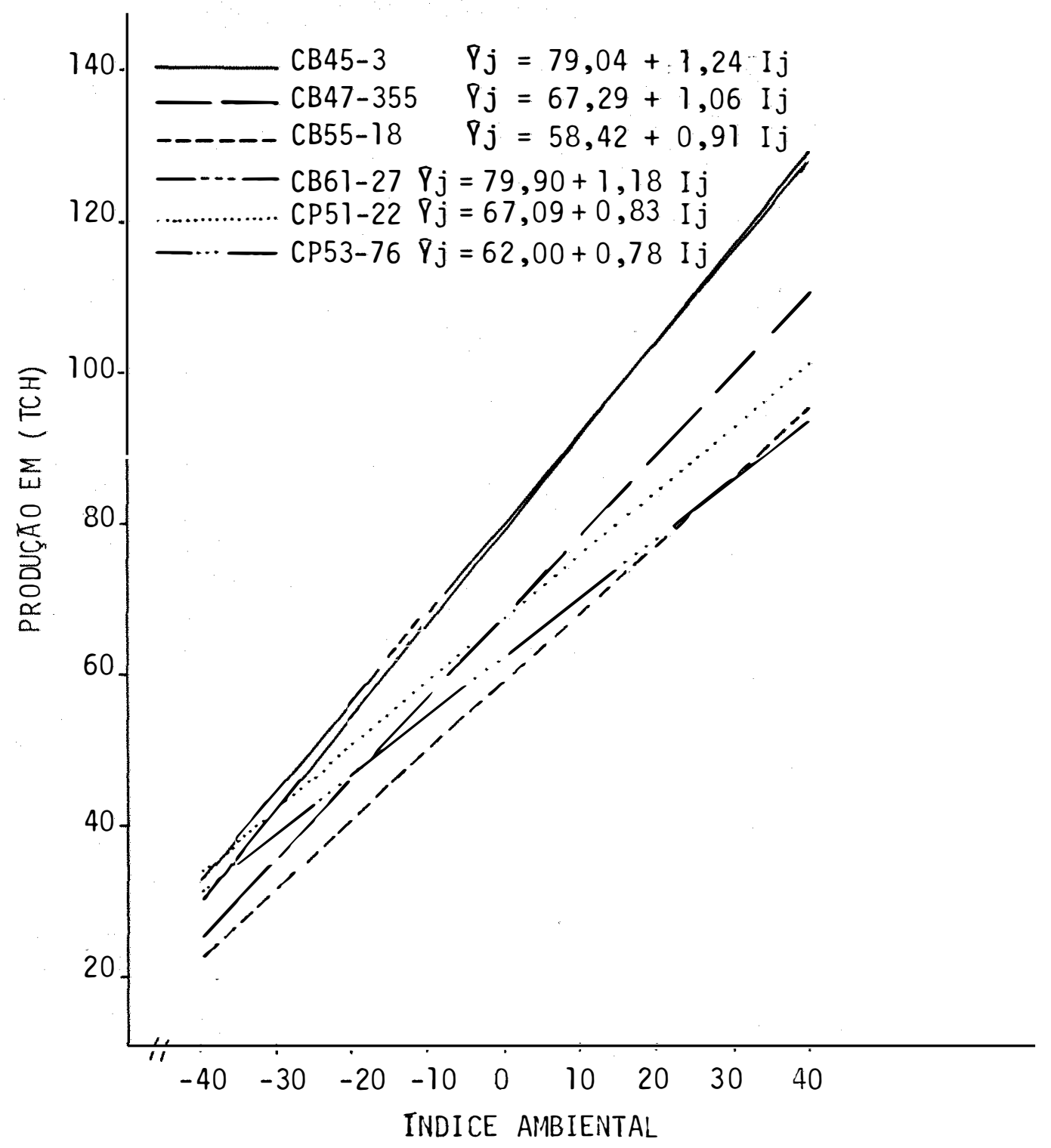

FIgURA 1 - Regressão linear da produção de cana-de-açūcar das seis variedades em 58 ambientes. 
53.

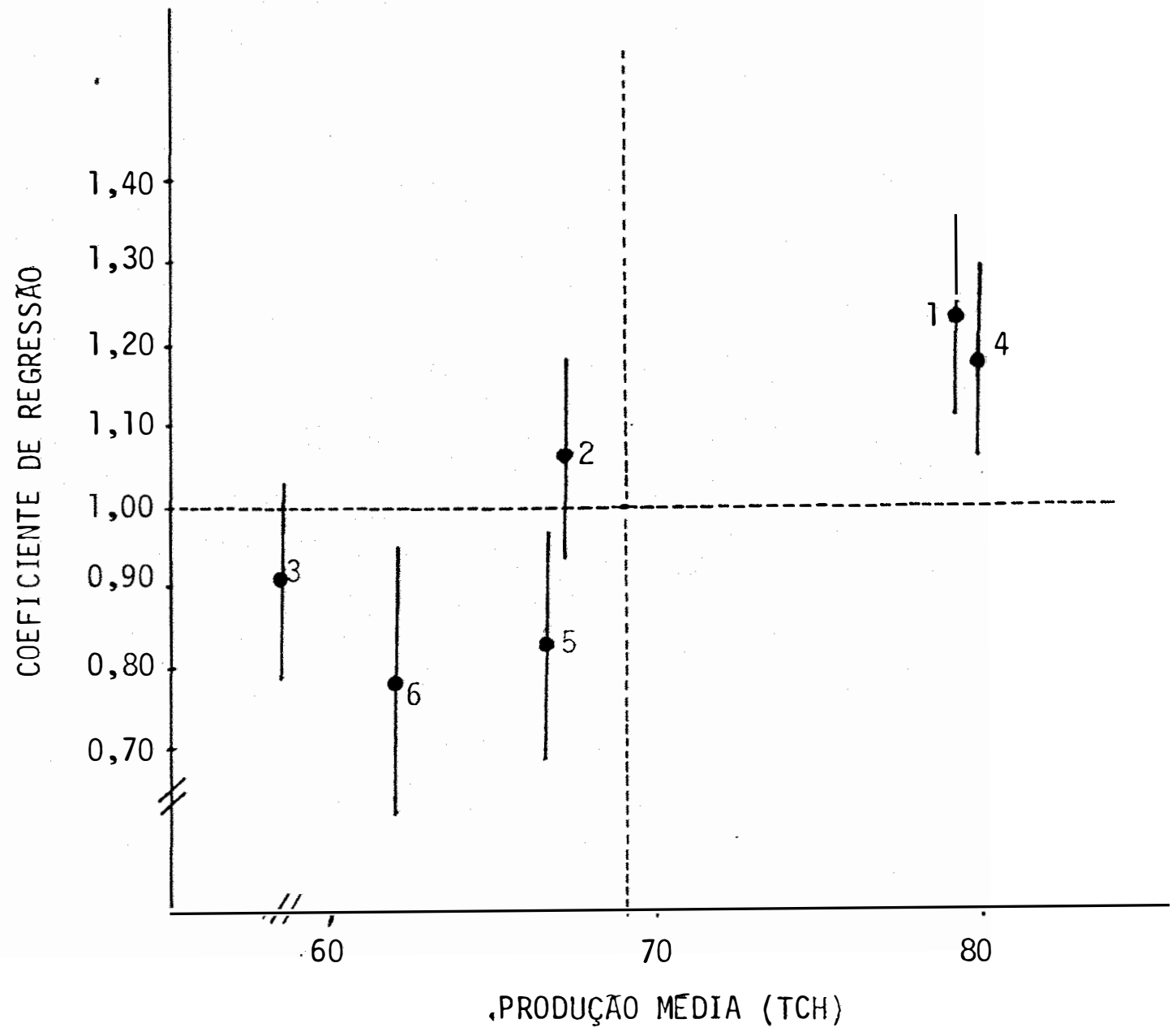

Os números identificam as variedades:

$$
\begin{aligned}
& 1=C B 45-3 ; 2=C B 47-355 ; 3=C B 55-18 ; \\
& 4=C B 61-27 ; 5=C P 51-22 ; 6=C P 53-76 . \\
& \phi=b \pm t_{0,05} \cdot s(b), \text { onde } t_{0,05}=2,018(G L=56) .
\end{aligned}
$$

FIGURA 2 - Relação entre a produção média de cana-de-açūcar e coeficientes de regressão linear das seis variedades em 58 ambientes. 
um corte para outro (Tabela 13, pāg. 36) tambēm não apresentạ ram a mesma ordenação e os coeficientes de determinação confirmam maior predomināncia dos efeitos lineares no segundo cor te. Estes resultados sugerem que o estudo de vārios ambientes em apenas um corte não fornece uma avaliação segura da estabi lidade fenotípica das variedades de cana-de-açúcar.

Neste particular, é interessante discutir alguns aspectos relacionados à seleção em cana-de-açūcar. De uma maneira geral, nas trēs primeiras etapas de seleção, ape nas a cana-planta (primeiro corte) é considerada. Exceção ocorre para os clones originados de cruzamentos especificos e biparentais, para os quais na primeira etapa de seleção consi dera-se a cana-soca (segundo corte), mas as duas etapas seguintes seguem o mesmo processo utilizado com os clones origi nados de cruzamentos múltiplos (seleção apenas da cana-plan ta). A utilização ūnica da cana-planta no processo de seleção de cada etapa, pode ser justificada pela grande quantidade de clones existentes nas primeiras etapas quando espaço e tempo forem fatores limitantes. Na primeira etapa de seleção, os clo nes são ensaiados a partir de sementes sexuadas e a seleção tem por finalidade eliminar somente os clones com comportamen tos acentuadamente inferiores. Estes fatores minimizam a desvantagem da seleção ser baseada apenas na cana-planta.

Procedimentos diferentes são utilizados na segunda etapa de seleção. Nesta etapa, os clones são ensaiados 
- a partir de propágúlos vegetativos e a seleção praticada é mais intensa. Conseqüentemente, esta seleção deve ser mais crí teriosa que a seleção praticada na primeira etapa. Seria dese jāvel que, nesta segunda etapa, a seleção fosse baseada na cana-soca, ambiente no qual as variedades mostram comportamen tos mais estáveis. Neste sentido, os seguintes procedimentos são sugeridos: antecipar de trēs a quatro meses a seleção de clones na primeira etapa e a instalação do experimento para $\underline{i}$ nício da segunda etapa; na segunda etapa, realizar o primeiro corte, sem seleção, após trēs a quatro meses do plantio; na fase normal, praticar a seleção e instalar a próxima etapa. De acordo com esta sugestão, a seleção dos clones na segunda etapa passaria a ser baseada em cana-soca.

\subsection{Avaliação da Repetibilidade dos Parâmetros de ESTABILI DADE}

As estimativas dos parāmetros de estabilidade a partir de dois grupos de informação, um considerando as duas primeiras repetições e o outro considerando as duas ūitimas repetições de cada experimento (Apēndice 3, pāg. 69), permiti ram a realização do estudo de repetibilidade.

A repetibilidade dos trēs parāmetros (médias de produção, b e $\mathrm{s}_{\mathrm{d}}^{2}$ ), considerando os dois cortes (Tabelas 14, 
pāg. 38; 15, pág. 39 e 16, pāg. 40) sugerem que a seleção pode ser eficiente para estas caracteristicas. Estes resultados concordam com o obtido por BONATO (1978) em soja, para os parâmetros produção média e coeficientes de regressão linear, discordando no que se refere à variāncia dos desvios da regressão. Em relação ao trabalho de SANTOS (1980) com feijão, existe concordāncia apenas com a repetibilidade da produção média. Isto significa, que a base genética destas características são diferentes de uma cultura para outra, o que se justifica plenamente por ser a cana-de-açūcar alógama e o feijão e a soja autógamas.

Para os parāmetros produção média e coeficiente de regressão linear, a repetibilidade praticamente não se alterou de um corte para outro (Tabelas 14, pág. 38 e 16, pág. 39). Entretanto, para as variāncias dos desvios da linearidade, os valores de repetibilidade foram discordantes de um cor te para outro $\left(r_{i}=0,6770\right.$ e $-0,2012$, respectivamente para 0 primeiro e segundo cortes). Considerando o erro associado à estimativa de $r_{j}$, a repetibilidade da variāncia dos desvios no segundo corte $(r=-0,2012)$ pode ser considerada nula, pois $r_{i}=-0,2012 \pm 0,6764$. A ausēncia de variação genética para a variāncia dos desvios da linearidade no segundo corte, provavelmente é devida aos baixos valores das variāncias nos gru pos I e II (Apēndice 3, pág. 70, segundo corte). Estes valores baixos são esperados se se considerar a maior predomināncia de efeitos lineares no segundo corte (Tabela 10, pág. 33). 
Este fato vem reforçar a evidéncia jā discutida, de que a seleção praticada no segundo corte deve ser mais promissora que a seleção praticada no primeiro corte. 


\section{CONCLUSÕES}

Os resultados obtidos no presente estudo permi tem concluir para as regiões canavieiras dos Estados de Per nambuco e Rio Grande do Norte:

a) Cortes consecutivos devem ser considerados como ambientes no estudo de estabilidade fenotípica em cana-de-açúcar;

b) 0 segundo corte apresenta nível mais alto de estabilidade do que o primeiro corte;

c) A estabilidade fenotīpica é melhor avaliada quando se considera mais de um corte;

d) As variedades CB45-3 e CB61-27 mostraram melhor adaptação a ambientes mais favoráveis;

e) As variedades CP51-22 e CP53-76, procedentes de Canal Point (Flōrida, EUA) mostraram melhor adaptação a condições desfavoráveis e apresentaram comportamento menos previsivel 
que as variedades procedentes de Campos (Rio de Janeiro, Brasil);

f) Existem evidēncias de que a seleção realizada sobre a cana-soca é mais eficiente que na cana-planta;

g) Existem possibilidades promissoras para se alterar tanto a produção como também as respostas lineares e não-lineares às variações ambientais, com a prática de seleção em canade-açūcar. 


\section{$\overline{7}$. LITERATURA CITADA}

ALLARD, R.W. e A.D. BRADSHAW, 1964. Implications of genotypeenvironmental interactions in applied plant breeding. Crop Sci. Madison, 4: 503-508.

BENNETT, C.A. e N.L. FRANKLIN, 1963. Statistical anatysis in chemistry and the chemical industry. N.Y. John Wiley \& Sons, Inc., 3a imp., $724 \mathrm{p}$.

BHULLAR, G.S.; K.S. GILL e A.S. KHEHRA, 1977. Stability analys is over various filial generations in bread wheat. Theor. Appl. Genet. Berlin, 51: 41-44.

BILBRO, J.D. e L.L. RAY, 1976. Environmental stability and adaptation of several cotton cultivars. Crop Sci. Madison, 16: $821-824$.

BONATO, E.R., 1978. Estabilidade fenotīpica da produção de grãos de dez cultivares de soja [GZycine max (L.) Merril] nas condições do Rio Grande do Sul. Piracicaba, ESALQ/USP, 75p. (Dissertação de Mestrado). 
BREESE, E.L., 1969. The measurement and significance of genotypeenvironment interactions in grasses. Heredity...Edinburgh, 24: $27-44$.

BUCIO ALANIS, L., 1966. Environmental and genotype-environmental components of variability. I. Inbred lines. Heredity. Edinburgh, 21: 387-397.

BUCIO ALANIS, L. e J. HILL, 1966. Environmental and genotypeenvironmental components of variability. II. Heterozygotes. Heredity. Edinburgh, 21: 399-405.

BUCIO ALANIS, L.; J.M. PERKINS e J.L. JINKS, 1969. Environmental and genotype-environmental components of variability. V. Segregating generations. Heredity. Edinburgh, 24: 115-127.

CALHEIROS, G.C., 1978. Estabilidade de variedades de cana-deaçūcar (Saccharum spp.) no Estado de Alagoas. Piracicaba, ESALQ/USP, 53p. (Dissertação de Mestrado).

COMSTOCK, R.E. e MOLL, R.H., 1963. Genotype-Environment interactions. In: Statistical Genetics and Plant Breeding. Washington, Nat. Acad. Sci. Nat. Res. Council, publ. 982, p.164-196.

ESPINOSA, R. e G. GALVEZ, 1980. The interaction of the genotypes with planting dates and harvest cycles in sugarcane. (Apre sentado ao International Society of Sugarcane Technologists, 17, Manila).

EASTON, H.S. e R.J. CLEMENTS, 1973. The interaction of wheat genotypes with a specific factor of the environment. $\mathrm{J}$. Agric. Sci.. London, 80: 43-52. 
EBERHART, S.A. .e W.A. RUSSELL, 1966. Stability parameters for comparing varieties. Crop. Sci. Madison, 6: 36-40.

FANGUY, H.P., 1971. Brittleness of sugarcane varieties in Louisiana. Proc. ISSCT. 13: 381-385.

FINLAY, K.W. e G.N. WILKINSON, 1963. The analys is of adaptation in a plant-breeding programme. Aust. J.Agric. Res. Victoria, 14: 742-754.

GALVEZ, G., 1980. The genotype-environment interactions in experiments of sugarcane variety trials (Saccharum spp.): comparison of three stability methods. (Apresentado ao International Society of Sugarcane Technologists, 17., Manila).

GEORGE, E.F., 1963. A further study of Saccharum progenies in contrasting environments. Proc. ISSCT. 11: 488-497.

HILL, J. e C.J.A. SAMUEL, 1971. Measurement and inheritance of environmental response amongst selected material of Lolium perene. Heredity, 27: 265-276.

JENSEN, N.F., 1965. Multiline superiority in cereals. Crop. Sci. Madison, $\underline{5}$ : 566-568.

JOWETT, D., 1972. Yield stability parameters for sorghum in East Africa. Crop. Sci. Madison, 12: 314-317.

KALTSIKES, P.J. e E.N. LARTER, 1970. The interaction of genotype and environment in durum wheat. Euphytica. Wageningen, 19: 236-242. 
LUTHRA, O.P. e R.K. SINGH, 1974. A comparison of different stability models in wheat. Theor. Appl. Genetics. Berlin, 45: $143-149$.

MARIOTTI, J.A., 1974. The effect of Environments of the Effectiveness of Clonal Selection in Sugarcane. Proc. ISSCT. 15: $89-95$.

MARIOTTI, J.A.; E.S. OYARZABAL; J.M. OSA; A.N.R. BULACIO e G. H. ALMADA, 1976. Analis is de estabilidad y adaptabilidad de genotipos de caña de azūcar. I. Interacciones dentro de una localidad experimental. Rev. Agron. N.0. Argent., $\underline{X I I I}(1-4): 105-127$.

MARIOTTI, J.A., 1980. Clonal selection a cross environments on sugarcane. (Apresentado ao International Society of Sugarcane Technologists, 17., Manila).

MONTEIRO, M.S.R., 1975. Comportamento heterōtico e estabilidade fenotípica em híbridos de berinjela (Solanum melongena L.). Piracicaba, ESALQ/USP, 81p. (Dissertação de Mestrado).

OLIVEIRA, A.C., 1976. Comparação de alguns métodos de determinação da estabilidade em plantas cultivadas. Brasilita, UnB., 64p. (Dissertação de Mestrado).

PERKINS, J.M. e J.L. JINKS, 1968. Environmental an genotypeenvironmental components of variability. III. Multiple lines and crosses. Heredity. Edinburgh, 23: 339-356.

PIMENTEL GOMES, F., 1976. Curso de Estatística Experimental. 6a ed. Piracicaba, Livraria Nobel S.A. 430p. 
PIRES, C.E.L.S. e E.F.S. COSTA, 1980. Association between some characters of sugarcane (Saccharum spp.) growing in four localities in the Northeast of Brazil. (Apresentado ao International Society of Sugarcane Technologists, 17., Manila).

PLAISTED, R.L., 1960. A shorter method for evaluating the ability of selections to yield consistently over locations. Amer. Potato J. Maine, 37: 166-172.

PLAISTED, R.L. e L.C. PETERSON, 1959. A technique for avaluating the ability of selections to yield consistently in different locations or seasons. Amer. Potato J. Maine, 36: 381-385.

POLLOCK, J.S., 1975. Selection consequences of differential performance of standard clones across environments. Sugar Breeder's Newsletter, 35: 36-41.

RUSCHEL, R., 1977. Phenotypic stability of some sugar cane varieties (Saccharum spp.) in Brazil. Proc. ISSCT. 16: $275-281$.

SANTOS, J.B., 1980. Estabilidade fenotípica de cultivares de feijão (Phaseolus vulgaris L.) nas condições do Sul de Minas Gerais. Piracicaba, ESALQ/USP, 110p. (Dissertação de Mestrado).

SKINER, J.C., 1971. Selection in sugarcane: A review. Proc. ISSCT, 13: 149-161.

STEEL, R.G.D. e J.H. TORRIE, 1960. Principles and Procedures of Statistics. New York, McGraw-Hill Book Company, Inc. $481 p$. 
TAI, G.C.C., 1971. Genotypic stability analysis and its application to potato regional trials. Crop. Sci. Madison, 11: $184-190$.

VELLO, N.A. e R. VENCOVSKY, 1978. Erros associados às estimativas de parāmetros genēticos. Trabalho apresentado na "Reunião Comemorativa dos noventa anos do Instituto Agronō mico". Região Brasileira da Sociedade Internacional de Biometria. Campinas, São Paulo. 7p. (Mimeografado).

YATES, F. e M.G. COCHRAN, 1938. The analysis of group of experiments. J.Agric. Sci. London, 28: 556-580.

ZONTA, E.P., 1978. Anālise conjunta de experimentos em parcelas subdivididas. Piracicaba, ESALQ/USP, 18p. (Seminārio mimeografado). 
66.

8 - APẼNDICE 
APENDICE 1.- Produções mēdias I! $(T C H)$ de seis variedades de cana-de-açūcar, variāncias dos resíduos $\left(s^{2}\right)$, média geral $(\bar{Y} . j)$ e coeficientes de variação, correspondentes ao primeiro corte de 29 experimentos.

\begin{tabular}{|c|c|c|c|c|c|c|c|c|c|}
\hline \multirow{2}{*}{ Ambientes } & \multicolumn{6}{|c|}{ VARIEDADES } & \multirow[b]{2}{*}{$\mathrm{s}^{2}$} & \multirow[b]{2}{*}{$\bar{Y} . j$} & \multirow[b]{2}{*}{ CV\% } \\
\hline & CB45-3 & CB47-355 & CB55-18 & CB61-27 & CP51-22 & CP53-76 & & & \\
\hline 01 & 95,95 & 60,78 & 70,80 & 77,58 & 75,80 & 73,00 & 83,49 & 75,65 & 12,08 \\
\hline 02 & 99,63 & 91,55 & 67,78 & 99,04 & 75,10 & 90,78 & 77,14 & 87,31 & 10,06 \\
\hline 03 & 74,00 & 64,45 & 53,63 & 78,80 & 67,43 & 65,35 & 63,05 & 67,28 & 11,80 \\
\hline 04 & 77,05 & 60,03 & 48,98 & 77,68 & 62,33 & 65,33 & 40,35 & 65,23 & 9,74 \\
\hline 05 & 67,78 & 49,50 & 46,03 & 63,00 & 53,28 & 53,23 & 109,63 & 55,47 & 18,88 \\
\hline 06 & 97,58 & 71,08 & 70,33 & 90,50 & 73,63 & 68,55 & 29,26 & 78,61 & 6,88 \\
\hline 07 & 102,95 & 91,88 & 73,78 & 101,53 & 81,40 & 82,60 & 94,88 & 89,02 & 10,94 \\
\hline 08 & 137,23 & 81,70 & $-65,48$ & 135,50 & 129,08 & 44,13 & 217,29 & 98,85 & 14,91 \\
\hline 09 & 105,33 & 72,70 & 85,20 & 101,95 & 88,80 & 75,75 & 99,40 & 88,29 & 11,29 \\
\hline 10 & 92,63 & 76,18 & 82,78 & 98,58 & 76,63 & 65,98 & 49,75 & 82,13 & 8,59 \\
\hline 11 & 113,58 & 109,38 & 79,48 & 105,23 & 82,93 & 91,45 & 271,61 & 97,01 & 16,99 \\
\hline 12 & 77,30 & 75,58 & 62,90 & 85,98 & 60,45 & 63,85 & 81,42 & 71,01 & 12,71 \\
\hline 13 & 76,70 & 69,73 & 64,58 & 86,38 & 56,08 & 66,80 & 52,99 & 70,05 & 10,39 \\
\hline 14 & 88,43 & 87,28 & 73,05 & 94,00 & 67,43 & 78,80 & 88,57 & 81,50 & 11,55 \\
\hline 15 & 92,98 & 88,78 & 60,43 & 91,80 & 96,15 & 52,33 & 61,59 & 80,41 & 9,76 \\
\hline 16 & 100,38 & 67,75 & 56,78 & 86,80 & 85,00 & 42,10 & 124,73 & 73,14 & 15,27 \\
\hline 17 & 82,60 & 59,83 & 49,73 & 77,53 & 73,73 & 56,03 & 55,26 & 66,58 & 11,17 \\
\hline 18 & 94,25 & 89,50 & 45,28 & 66,53 & 76,80 & 86,40 & 200,82 & 76,46 & 18,53 \\
\hline 19 & 127,98 & 97,80 & 64,88 & 107,50 & 75,10 & 73,13 & 204,07 & 91,07 & 15,69 \\
\hline 20 & 119,85 & 106,35 & 104,35 & 115,13 & 82,90 & 87,40 & 114,38 & 102,60 & 10,42 \\
\hline 21 & 94,50 & 69,80 & 71,35 & 95,78 & 74,80 & 70,80 & 69,26 & 79,51 & 10,47 \\
\hline 22 & 106,73 & 98,98 & 88,48 & 107,73 & 91,95 & 88,38 & 41,80 & 97,04 & 6,66 \\
\hline 23 & 87,45 & 80,95 & 70,03 & 63,93 & 84,00 & 80,58 & 72,54 & 77,82 & 10,94 \\
\hline 24 & 63,18 & 64,00 & 50,78 & 74,75 & 53,10 & 59,38 & 64,16 & 60,87 & 13,16 \\
\hline 25 & 52,88 & 60,45 & 49,73 & 58,75 & 53,10 & 58,13 & 34,67 & 55,51 & 10,61 \\
\hline 26 & 60,75 & 61,55 & 50,93 & 62,10 & 59,23 & 63,80 & 74,39 & 59,73 & 14,44 \\
\hline 27 & 37,98 & 45,35 & 55,63 & 48,00 & 48,68 & 54,95 & 27,67 & 48,43 & 10,86 \\
\hline 28 & 62,80 & 59,60 & 44,93 & 74,00 & 76,65 & 43,73 & 60,69 & 60,29 & 12,92 \\
\hline 29 & 88,85 & 65,15 & 81,63 & 100,00 & 97,35 & 52,00 & 168,85 & 80,83 & 16,08 \\
\hline
\end{tabular}

If Obtidas a partir do Apéndice 5. 


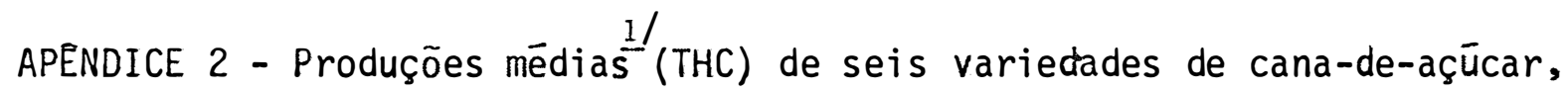
vàriāncia do resíduo $\left(s^{2}\right)$, média geral $(Y . j)$ dos ambientes e coeficiente de variação correspondentes ao segundo corte de 29 experimentos.

\begin{tabular}{|c|c|c|c|c|c|c|c|c|c|}
\hline \multirow[t]{2}{*}{ Anbientes } & \multicolumn{6}{|c|}{ VARIEDADES } & \multirow[b]{2}{*}{$s^{2}$} & \multirow[b]{2}{*}{$\bar{Y} \cdot j$} & \multirow[b]{2}{*}{ CV\% } \\
\hline & CB45-3 & CB47-355 & CB55-18 & CB61-27 & CP51-22 & CP53-76 & & & \\
\hline 1 & 42,93 & 24,55 & 28,65 & 30,85 & 35,88 & 33,76 & 31,84 & 32,77 & 17,22 \\
\hline 2 & 80,58 & 56,30 & 53,75 & 79,78 & 66,30 & 71,70 & 109,16 & 68,07 & 15,35 \\
\hline 3 & 69,55 & 64,75 & 45,00 & 73,55 & 58,23 & 53,98 & 39,72 & 60,84 & 10,25 \\
\hline 4 & 81,28 & 63,00 & 52,85 & 78,55 & 59,85 & 73,30 & 74,04 & 68,14 & 12,63 \\
\hline 5 & 60,87 & 54,13 & 39,28 & 68,00 & 51,50 & 45,40 & 83,79 & 53,20 & 16,62 \\
\hline 6 & 84,63 & 66,35 & 59,25 & 83,93 & 65,55 & 50,98 & 81,72 & 68,45 & 13,21 \\
\hline 7 & 74,03 & 56,13 & 42,33 & 72,65 & 53,03 & 56,55 & 38,90 & 59,12 & 10,55 \\
\hline 8 & 7ו,93 & 46,28 & 54,50 & 65,40 & 56,90 & 32,25 & 70,10 & 54,54 & 15,35 \\
\hline 9 & 88,58 & 63,85 & 63,00 & 91,35 & 75,88 & 64,83 & 70,78 & 74,58 & 11,28 \\
\hline 10 & 81,65 & 59,53 & 51,43 & 103,00 & 67,98 & 61,43 & 55,93 & 70,84 & 10,56 \\
\hline 11 & 70,70 & 55,38 & 34,53 & 63,65 & 50,33 & 43,79 & 94,12 & 53,06 & 17,66 \\
\hline 12 & 94,88 & 89,05 & 70,93 & 106,18 & 61,63 & 80,13 & 84,34 & 83,80 & 10,96 \\
\hline 13 & $99 ; 45$ & 89,48 & 81,50 & 109,18 & 65,90 & 87,93 & 40,16 & 88,91 & 7,13 \\
\hline 14 & 86,28 & 90,68 & 85,20 & 104,73 & 79,55 & 74,93 & 77,20 & 86,90 & 10,11 \\
\hline 15 & 43,23 & 52,85 & 45,60 & 61,50 & 45,88 & 42,98 & 33,45 & 48,67 & 11,88 \\
\hline 16 & 63,00 & 70,38 & 50,93 & 75,93 & 61,08 & 42,00 & 52,38 & 60,55 & 11,95 \\
\hline 17. & 34,15 & 22,03 & 24,65 & 35,48 & 35,48 & 28,50 & 67,51 & 30,05 & 26,42 \\
\hline 18 & 39,43 & 32,38 & 26,63 & 36,38 & 41,95 & 33,33 & 80,69 & 35,02 & 25,66 \\
\hline 19 & 56,48 & 47,18 & 42,48 & 56,65 & 50,78 & 42,93 & 59,60 & 49,42 & 15,73 \\
\hline 20 & 95,75 & 97,05 & 89,55 & 95,58 & 75,95 & 86,10 & 56,27 & 90,00 & 8,34 \\
\hline 21 & 65,88 & 55,45 & 46,10 & 60,05 & 53,50 & 58,25 & 58,05 & 56,54 & 13,48 \\
\hline 22 & 56,58 & 49,95 & 42,73 & 48,08 & 48,90 & 59,40 & 35,85 & 50,94 & 11,75 \\
\hline 23 & 67,83 & 68,33 & 56,28 & 72,28 & 56,60 & 61,35 & 57,25 & 63,78 & 11,86 \\
\hline 24 & 67,40 & 55,45 & 47,03 & 76,50 & 62,40 & 50,07 & 45,61 & 60,81 & 1ו, ו1, \\
\hline 25 & 69,30 & 57,78 & 55,00 & 62,20 & 66,20 & 65,08 & 34,62 & 62,59 & 9,40 \\
\hline 26 & 67,50 & 78,75 & 59,18 & 84,28 & 76,23 & 74,70 & 71,17 & 73,44 & 11,48 \\
\hline 27 & 73,25 & 64,23 & 66,10 & 82,28 & 72,43 & 79,13 & 66,06 & 72,90 & 11,15 \\
\hline 28 & 53,23 & 48,30 & 34,95 & 61,60 & 55,30 & 42,43 & 48,58 & 49,30 & 14,14 \\
\hline 29 & 64,80 & 45,63 & 49,23 & 68,63 & 60,95 & 38,08 & 26,07 & 54,55 & 9,36 \\
\hline
\end{tabular}

1/ Obtidas a partir do Apêndice 6. 


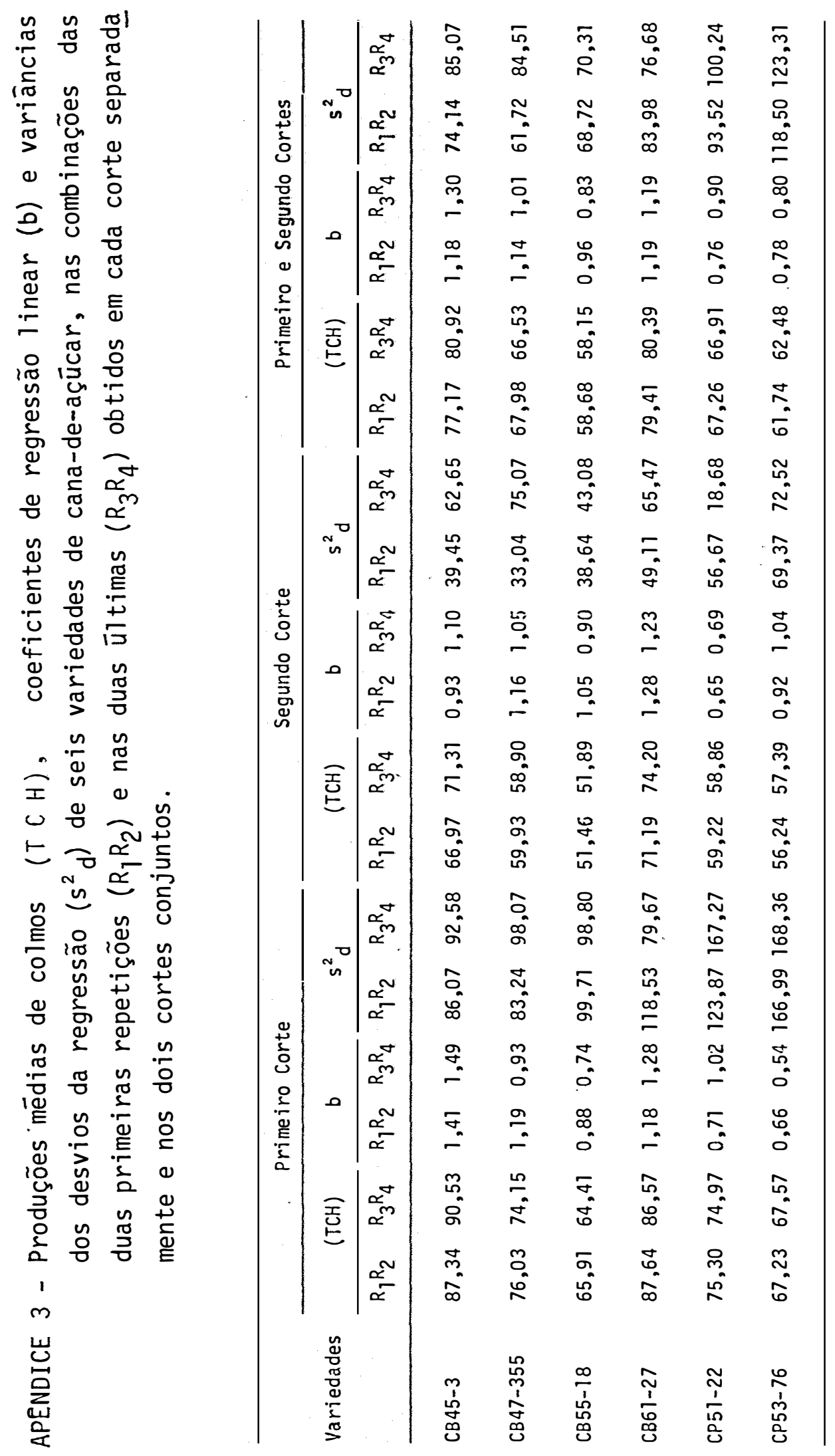




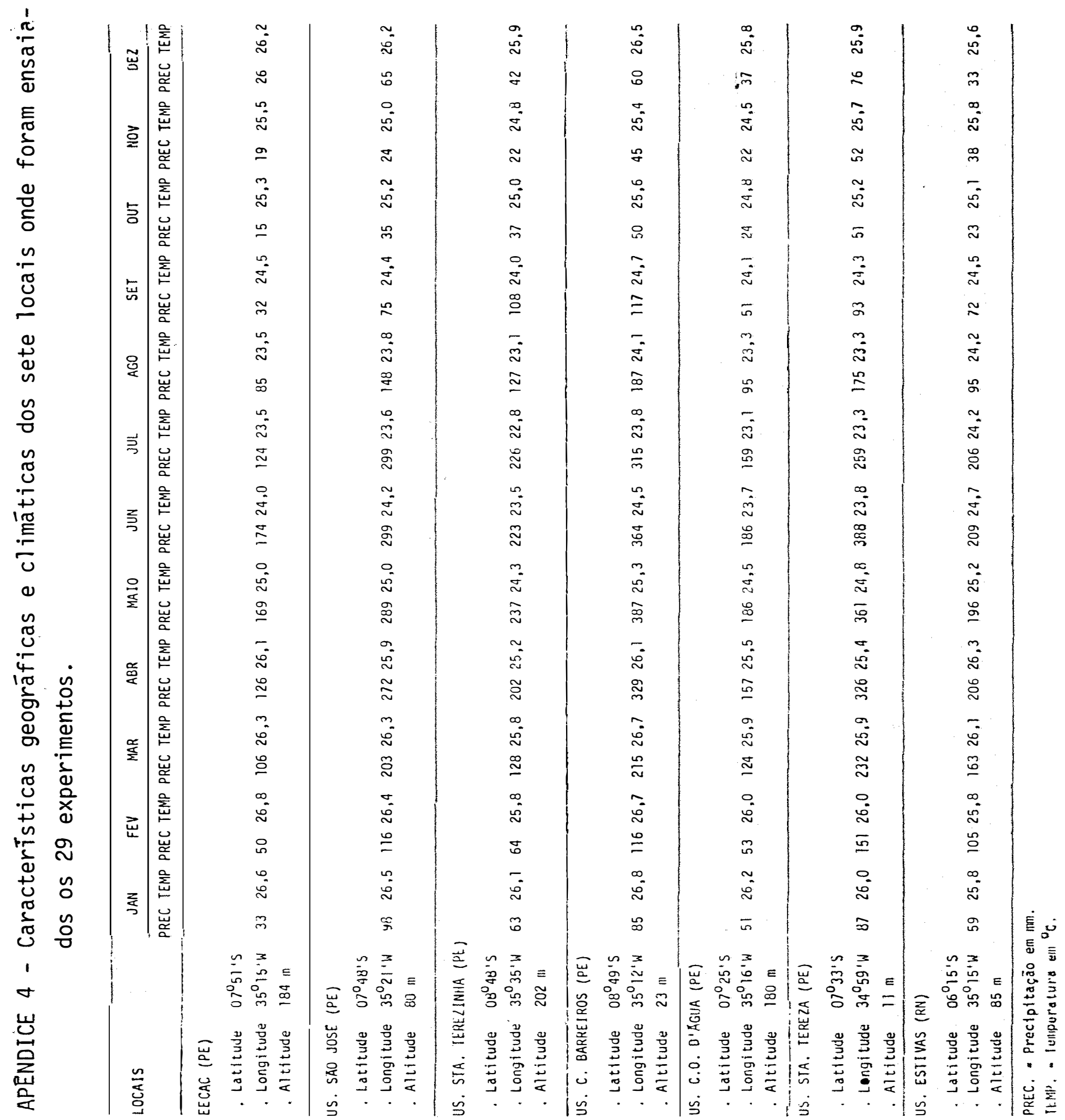




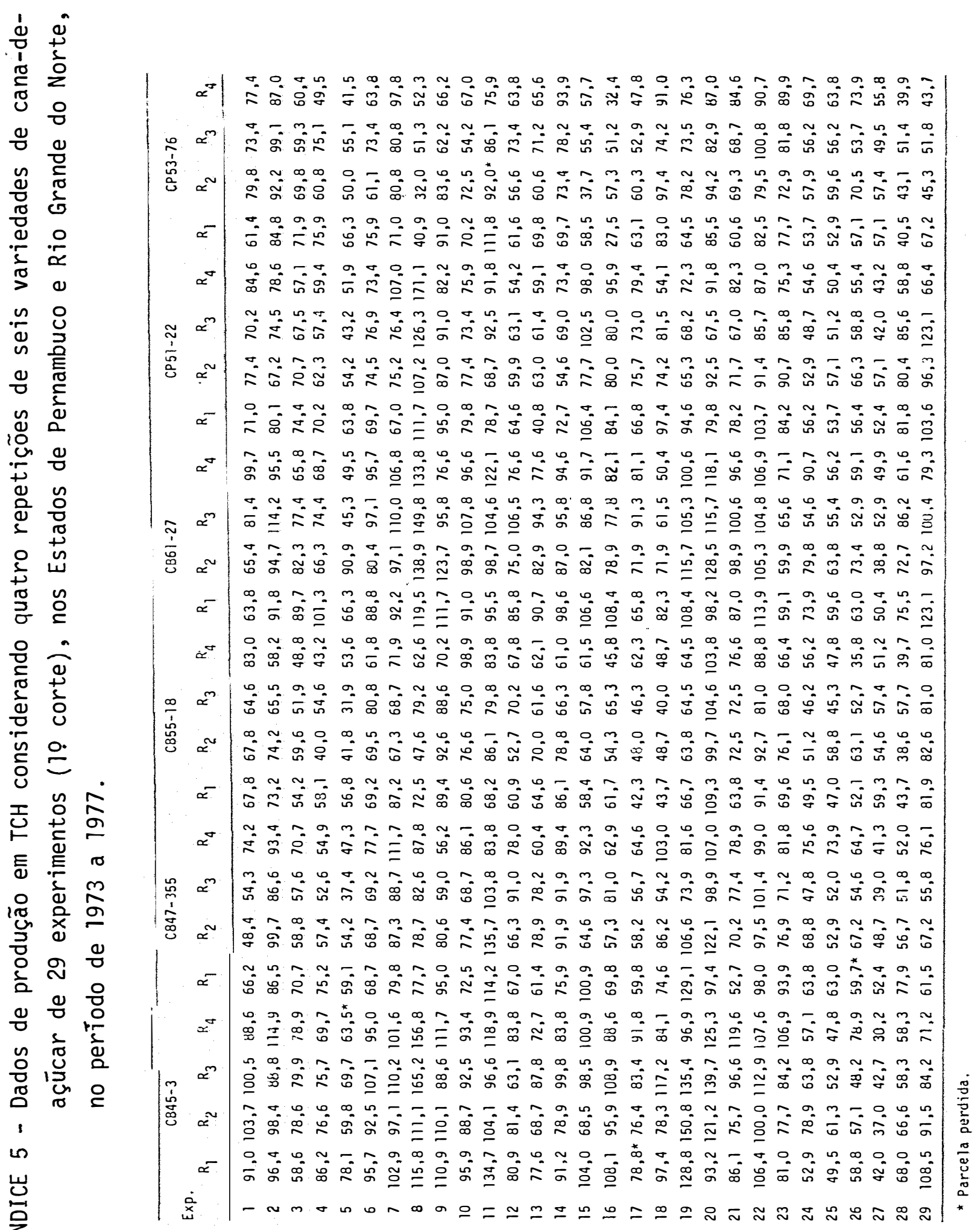




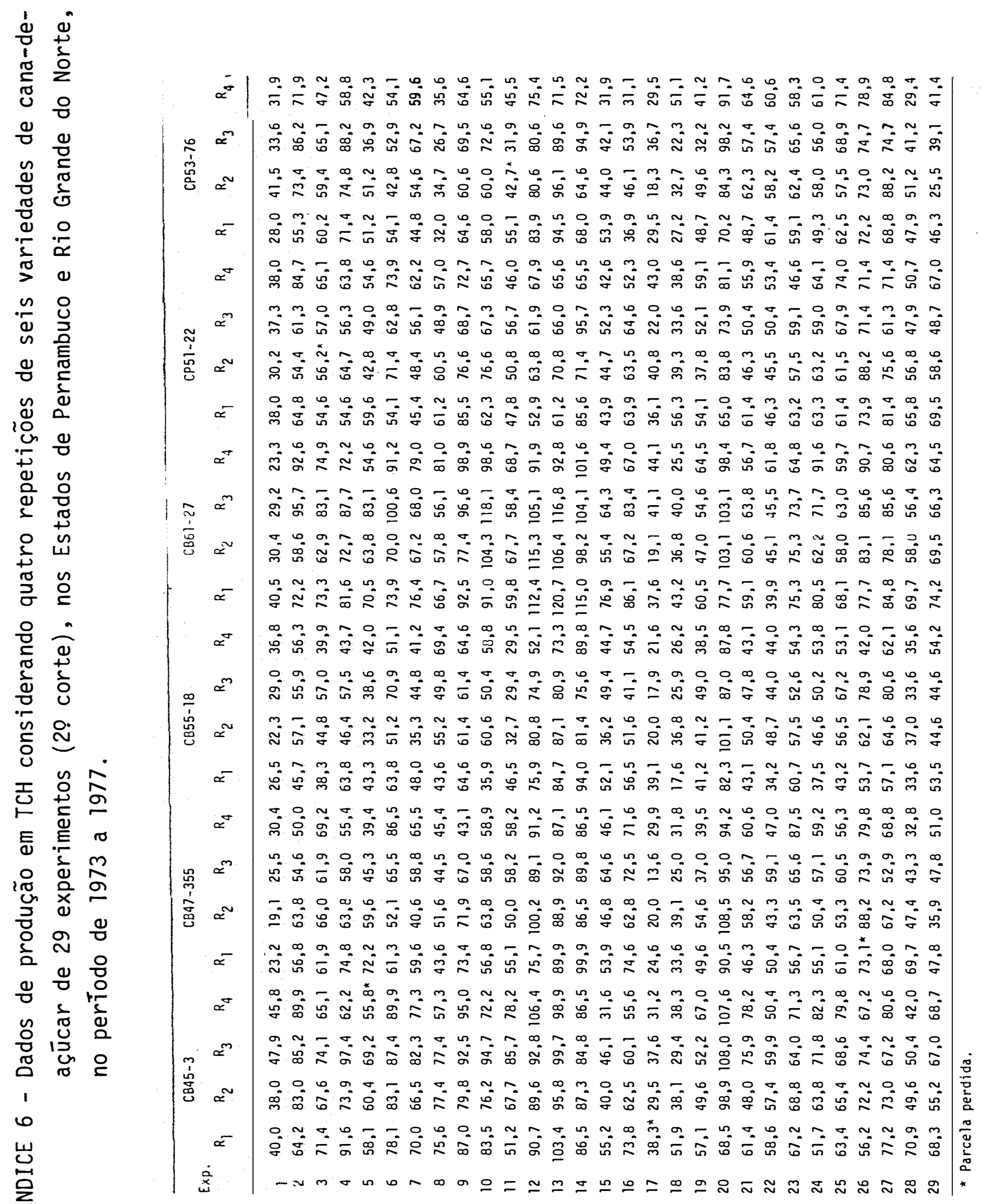

